\title{
POTENCIALIDADES E LIMITAÇÕES DO USO DE INFORMAÇÕES ALTIMÉTRICAS PROVENIENTES DE PERFILAMENTO À LASER EM AMBIENTE URBANO
}

\author{
Felipe Lima Ramos Barbosa \\ Universidade de Brasília, Departamento de Geografia, Brasília-DF, Brasil \\ felipelrb@gmail.com \\ Renato Fontes Guimarães \\ Universidade de Brasília, Departamento de Geografia, Brasília-DF, Brasil \\ renatofg@unb.br \\ Osmar Abílio de Carvalho Júnior \\ Universidade de Brasília, Departamento de Geografia, Brasília-DF, Brasil \\ osmarji@unb.br \\ Roberto Arnaldo Trancoso Gomes \\ Universidade de Brasília, Departamento de Geografia, Brasília-DF, Brasil \\ robertogomes@unb.br \\ Erondina Azevedo de Lima \\ Universidade de Brasília, Instituto de Física, Brasília-DF, Brasil \\ erondinaazevedo@unb.br
}

\begin{abstract}
RESUMO
A concentração da população brasileira residindo em ambientes urbanos demandam uma gestão eficiente do território e dos efeitos provenientes do escoamento hídrico, tais como erosão, inundações e movimento de massa. O presente trabalho tem como objetivo adequar para áreas urbanas a delimitação de Áreas de Sensibilidade Hidrológicas (ASH), utilizando o Índice Topográfico de Umidade (ITU). A área de estudo é a Região Administrativa de São Sebastião do Distrito Federal que apresenta expansão urbana recente e problemas de drenagem urbana. A pesquisa discute as potencialidades e limitações quanto à utilização de dados altimétricos provenientes de laser na derivação de Modelos Digitais de Elevação (MDE) e na estimativa do escoamento superficial. A aplicação do índice HSA em áreas urbanas necessita de metodologias específicas: redução da nuvem de pontos amostrais pela seleção de fatores relevantes para o fluxo da água, filtragem de artefatos, manutenção das feições urbanas que condicionam o direcionamento hídrico, eliminação da cobertura vegetal, dentre outros. Os resultados obtidos mostram o potencial de estabelecer áreas sensíveis dentro da rede urbana com alta precisão, considerando as influências da topografia local. Portanto, a pesquisa inova ao apresentar uma solução metodológica de estimativa de HSA para o ambiente urbano na escala local.
\end{abstract}

Palavras-chave: Modelo Digital de Elevação (MDE). LIDAR. Índice Topográfico de Umidade (ITU). Área Urbana.

\section{CAPABILITIES AND LIMITATIONS OF LASER SCANNING SYSTEM ALTIMETRICS INFORMATIONS APPLIED IN AN URBAN SETTLEMENT}

\begin{abstract}
The concentration of the Brazilian population living in urban environments requires efficiently manage the territory and the effects of water runoff, such as erosion, floods, and mass movement. This work aims to adapt the delimitation of Hydrological Sensitivity Areas (HSA) to urban areas, using the Topographic Wetness Index (TWI). The study area is the Administrative Region of São Sebastião, in the Federal District, which presents recent problems of urban expansion and urban drainage. The research discusses the potentials and limitations in the use of altimetric data from the laser profile in the derivation of Digital Elevation Models (DEM) and the estimation of surface runoff. The application of the HSA index in urban areas requires specific methodologies: reduction of the sample point cloud by the selection of relevant factors for the flow of water, filtering of artifacts, maintenance of urban features that condition the direction of the water, elimination of vegetation cover, among others. The results obtained show the potential to establish sensitive areas within the urban network with high precision considering the influences of the local topography. Therefore, the research
\end{abstract}

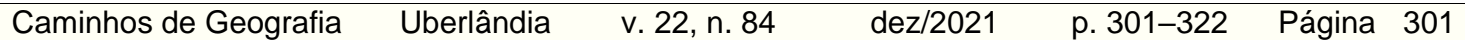


innovates by presenting a methodological solution to estimate HSA for the urban environment at a local scale.

Keywords: Digital Elevation Model (DEM). LIDAR. Topographic Wetness Index (TWI). Urban areas.

\section{INTRODUÇÃO}

Aparentemente, o Brasil possui satisfatórios valores de disponibilidade hídrica per capita, em comparação com outros países, tais como os europeus e os do Oriente Médio. No entanto, em média cerca de $260.000 \mathrm{~m} 3 / \mathrm{s}$ de água não é distribuída homogeneamente no território, dos quais 205.000 $\mathrm{m}^{3} / \mathrm{s}$ concentram-se na bacia hidrográfica do rio Amazonas e $55.000 \mathrm{~m}^{3} / \mathrm{s}$ nas demais áreas do território nacional (ANA, 2016). Essa distribuição heterogênea dos recursos hídricos brasileiros demonstra a necessidade de uma gestão sustentável.

Ressalta-se que, dos estimados 191 milhões de pessoas que residem no Brasil, cerca de 161 milhões (84,36\% da população) vivem no ambiente urbano (IBGE, 2010). Em 2050, projeções apontam um aumento para mais de $90 \%$ (ONU, 2018). Assim, é de suma importância considerar a dinâmica e o impacto da morfologia urbana no escoamento superficial, enchentes, erosões e movimentos de massa. Os modelos de dinâmica de relevo e de escoamento superficial da água são soluções estratégicas para a política pública preventiva (GUIMARÃES et al., 2003, 2017; CARVALHO JÚNIOR et al., 2010; FREITAS et al., 2012).

Grande parte das informações para inferências de modelos espaciais são provenientes da topografia. Diferentes técnicas e dados podem auxiliar na construção de representações digitais da elevação topográfica, conhecidos como Modelos Digitais de Elevação (MDE). A exemplo, podem ser citados os produtos provenientes do Shuttle Radar Thematic Mapper (SRTM), os métodos de interpolação de dados altimétricos amostrais provenientes do mapeamento cartográfico nacional, dentre outros.

Uma emergente técnica de levantamento topográfico é o sistema LIDAR (Light Detection and Ranging) que permite uma coleta rápida, precisa e densa de grandes volumes de dados georreferenciados na forma de nuvem de pontos tridimensionais. O sistema LIDAR permite diversas aplicações territoriais, tais como estudos dos aspectos biofísicos das árvores (IAF - índice de área foliar), planejamento urbano e levantamento topográfico de informações do terreno. $O$ alto grau de confiabilidade e rapidez torna essa técnica aplicável em terrenos inóspitos (MCGLONE, 2004).

O presente trabalho tem como objetivo adaptar para utilização em áreas urbanas a delimitação de Áreas de Sensibilidade Hidrológica (ASH) (WALTER et al., 2000) a partir do Índice Topográfico de Umidade (ITU). Para tanto, serão utilizados os dados altimétricos de perfilamento à laser (LIDAR) para a derivação de MDEs e a subsequente estimativa do escoamento superficial em áreas de expansão urbana recente no Distrito Federal. As informações são provenientes do aerolevantamento realizado pela Companhia Imobiliária de Brasília (Terracap) em uma porção da Região Administrativa de São Sebastião.

\section{LEVANTAMENTO TOPOGRÁFICO POR PERFILAMENTO À LASER}

Os sistemas LIDAR utilizados em mapeamentos topográficos são caracterizados como sistemas ativos de aquisição de dados levantamento ativo e utilizam o comportamento de retorno da luz laser na faixa do infravermelho próximo $(1.040 \mathrm{~nm}$ a $1.600 \mathrm{~nm})$ para obtenção da altimetria, a partir de técnica de varredura ótico-mecânica a bordo de plataformas aerotransportadas ou orbitais (JENSEN, 2011).

As informações altimétricas coletadas são obtidas a partir do intervalo de tempo (t) registrado entre a emissão do pulso laser, sua interação com o alvo e o registro do sinal de retorno, definido pela seguinte Equação (1) (MCGLONE, 2004).

$\mathrm{t}=2 \frac{\mathrm{R}}{\mathrm{c}}$

Onde $\mathrm{R}$ corresponde a distância entre o sensor LIDAR e o alvo, enquanto que, $\mathrm{c}$ é a velocidade da luz. Tendo em perspectiva a distância percorrida pelo pulso em sistemas aerotransportados ou orbitais, a luz laser sofre divergência em formato cônico, o que define a área de cobertura do pulso no terreno em 
formato circular, variando sua forma a depender do ângulo de varredura e da topografia local. $O$ diâmetro da visada instantânea laser (Fp) no terreno é calculada pela Equação (2) (BALTSAVIAS, 1999).

$\mathrm{Fp}=\frac{h}{\cos ^{2}(\Theta)} \Upsilon$

Onde $h$ equivale a altitude da plataforma em relação ao solo, $\Theta$ ao ângulo de varredura instantâneo e $\Upsilon$ a divergência do feixe laser. Outro importante fator é a Frequência de Repetição de Pulso (FRP), que pode apresentar valores superiores a 100.000 pulsos por segundo, o que torna possível o registro de um massivo quantitativo de informações altimétricas. Em sistemas aerotransportados, o levantamento das informações é realizado seguindo uma geometria perpendicular à linha de voo. A Figura 1 esquematiza o padrão de retornos esperados no levantamento.

Figura 1 - Representação do sinal de retorno em diferentes contextos de alvos.

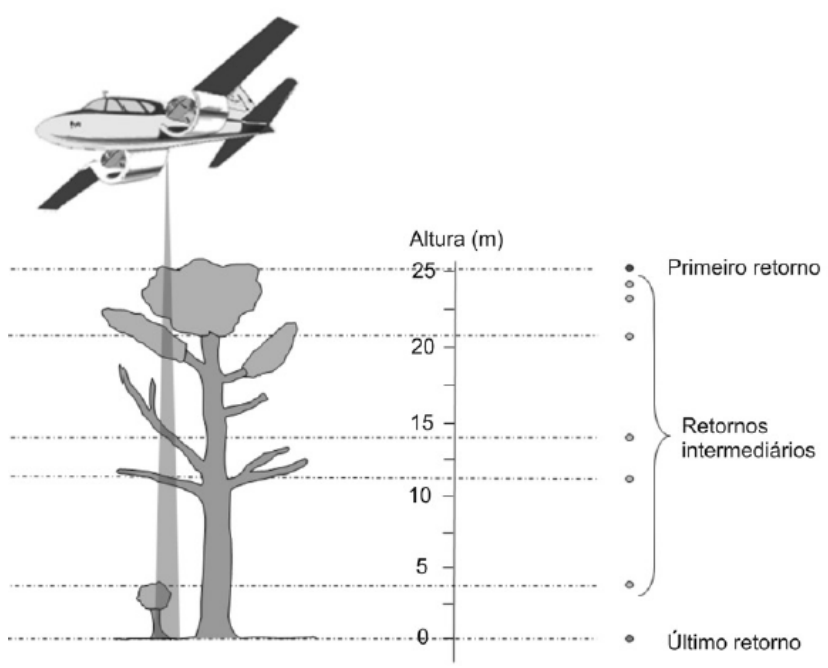

Fonte: Giongo et al., (2010)

Um dos métodos de perfilamento à laser comumente utilizado em aplicações topográficas consiste no aerolevantamento de um conjunto de pontos com dados de elevação, normalmente denominados de nuvem de pontos, distribuídos sistematicamente no tempo, ao longo da linha de voo (HODGSON et al., 2005; SHAN e TOTH, 2018). A disposição funcional do sistema LIDAR não permite ao usuário o controle da localização individual das medidas tridimensionais $(x, y, z)$ obtidas no levantamento. Apesar de, por outro lado, realizar a amostragem de localidades que seriam impossíveis de visitação utilizandose das técnicas convencionais (linhas de crista, vegetação densa, dentre outros).

O espaçamento de pontos perpendiculares à trajetória $\left(\mathrm{P}_{\mathrm{s}}\right)$ é o parâmetro que define o grau de densidade da nuvem de pontos altimétricos, e depende diretamente da frequência de repetição de pulso, da altitude da plataforma, da velocidade de varredura angular instantânea e do ângulo de varredura instantâneo, conforme a Equação (3) a seguir.

$\mathrm{P}_{\mathrm{S}}=\frac{h}{\cos ^{2}(\Theta)} x \frac{\alpha}{\mathrm{PRF}}$

Onde $h$ equivale a altitude da plataforma em relação ao solo, $\Theta$ ao ângulo de varredura instantâneo, $\alpha$ a velocidade de varredura angular instantânea, em radianos por segundo, e PRF a frequência de repetição de pulso. A densidade de amostragem para uma área depende, também, da velocidade da plataforma. Assim, o massivo conjunto amostral resultante do perfilamento à laser apresenta múltiplos retornos de determinadas situações (Figura 2). Isso permite capturar e estratificar com maior acurácia os alvos sobre a superfície da terra. Essa técnica permite um melhor controle procedimental na elaboração dos MDE e uma melhor adaptabilidade à diferentes aplicações técnicas e científicas (JENSEN, 2011).

$\begin{array}{llllll}\text { Caminhos de Geografia } & \text { Uberlândia - MG } & \text { v. 22, n. } 84 & \text { dez/2021 } & \text { p. 301-322 } & \text { Página } 303\end{array}$




\section{MODELO DIGITAL DE ELEVAÇÃO E CONSISTÊNCIA HIDROLÓGICA}

$\mathrm{Na}$ modelagem hidrológica, deve-se estabelecer etapas de consistência do MDE, tais como o preenchimento de depressões espúrias. Esse processamento visa garantir a conectividade do escoamento superficial no MDE a fim de assegurar a derivação de informações correlatas à direção preferencial, à acumulação de fluxo, a estimativa de área de contribuição, dentre outras. As depressões espúrias são comumente resultado da etapa de interpolação dos dados amostrais altimétricos durante a geração do MDE e, assim, sua eliminação visa garantir a máxima coincidência entre o trajeto de escoamento superficial da água no modelo, obtido de forma analítica, com a realidade em questão (HUTCHINSON, 1996).

Uma das propostas existentes na literatura, e bastante difundida, é a representação do caminho preferencial de escoamento superficial da água sobre o MDE, identificando o caminho descendente deste fluxo em cada célula do modelo. Exemplos de trabalhos que exploram esta abordagem são descritos pelos autores Quinn et al. (1991); Lea (1992); Costa-Cabral e Burges (1994), entre outros.

Diversas extensões de programas hoje existentes no mercado, tais como o ArcHydro (ESRI, 2020) e o TauDEM (TARBOTON, 2015), soluções livres que possuem uma coletânea de algoritmos, processados em workflow, visando tal consistência hidrológica do MDE, contendo procedimentos de preenchimento de depressões espúrias, estimativas de fluxos direcionais e acumulados, imposição de drenagem, dentre outros.

\section{ÍNDICE TOPOGRÁFICO DE UMIDADE E ÁREAS DE SENSIBILIDADE HIDROLÓGICA}

O ITU proposto por Beven e Kirkby (1979) permite uma rápida inferência de áreas com probabilidade de saturação e posterior ocorrência de escoamento superficial, sendo expresso pela Equação (4).

ITU $=\ln \left(\frac{\alpha}{\tan \beta}\right)$

Onde $\alpha$ representa a área de contribuição a montante e $\beta$ a declividade local. O ITU possibilita quantificar e qualificar o controle da topografia local quanto aos processos hidrológicos, bem como ressaltar as áreas com maior propensão ao escoamento superficial, contendo altos valores de área de contribuição e baixas declividades (LOTTE, ALMEIDA e VALERIANO, 2015). Ademais, esse índice possibilita a delimitação das $A S H$, contendo maiores susceptibilidades à saturação e geração de escoamento superficial (GRABS et al., 2009; THOMAS et al., 2017). O índice ITU por ser sensível à resolução do MDE evidencia as potencialidades e limitações dos sistemas LIDAR em aplicações topográficas (KIENZLE, 2004; THOMAS et al., 2017).

\section{MATERIAIS E MÉTODOS}

\section{Área de estudo}

A área de estudo compreende as articulações 171-IV-4-D e 171-IV-5-C do Mapeamento das Áreas Urbanas e Urbanizáveis do Distrito Federal na escala de 1:1.000, a partir de Levantamento Aerofotogramétrico de uma área aproximada de $1.201,15 \mathrm{~km}^{2}$, realizado em 2016 pela Companhia Imobiliária de Brasília - Terracap (TERRACAP, 2016). A área está localizada na Região Administrativa de São Sebastião (RA XIV), especificamente na região conhecida como "Morro da Cruz", entre as coordenadas geográficas $15^{\circ} 54^{\prime} 41^{\prime \prime} \mathrm{S}$ a $15^{\circ} 55^{\prime}$ " ${ }^{\prime \prime} \mathrm{S}$ em latitude e $47^{\circ} 45^{\prime} 56^{\prime \prime} \mathrm{O}$ a $47^{\circ} 46^{\prime} 34^{\prime \prime O}$ (Figura 2). 
Figura 2 - Localização da área de estudo no Distrito Federal e na Região Administrativa de São Sebastião.

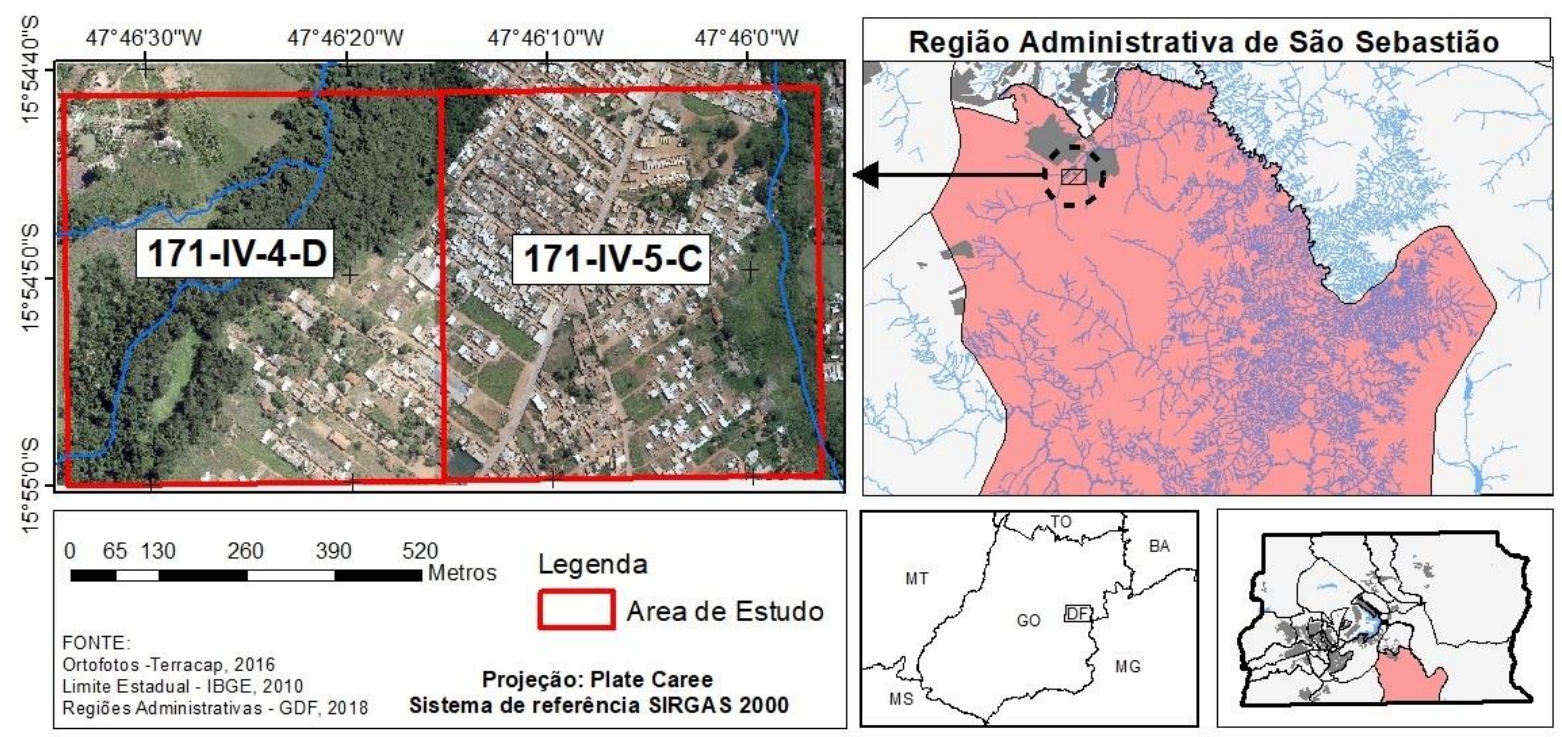

Fonte: Terracap, 2016; IBGE, 2010; GDF, 2018; Org. Autores

O mapeamento da Terracap de 2016 foi sistematizado em 3.729 folhas na escala 1:1.000, referenciadas ao SICAD-SIRGAS. O perfilamento à laser desse aerolevantamento possui densidade média de 4 pontos $/ \mathrm{m}^{2}$, cujo produto são nuvens de pontos de terreno (solo) e de superfície (feições localizadas acima do solo), ambas estratificadas em classes temáticas, bem como em número de retornos. Considerando as limitações de hardware, as inferências espaciais foram realizadas considerando as informações das articulações 171-IV-4-D e 171-IV-5-C, presentes na denominada "área 2" do referido projeto de levantamento.

Nos anos recentes, a irregular transformação de rural para urbana acarretou diversos impactos ambientais e sociais conforme o Zoneamento Ecológico-Econômico (ZEE) do Distrito Federal (GDF, 2018). Assim, a área de estudo foi escolhida como exemplo desse processo de rápida e desordenada transformação territorial e, principalmente, por se caracterizar como área de alta recorrência de inundações, conforme frequentemente noticiado pelos principais veículos de comunicação do Distrito Federal.

\section{Elaboração do MDE e consistência hidrológica}

Para a elaboração do MDE, as informações utilizadas foram: (i) dados de terreno e (ii) dados de superfície classificados como edifícios, ambos produtos derivados no mapeamento das áreas urbanas e urbanizáveis realizado em 2016 pela Terracap (TERRACAP, 2016). A intenção de considerar tais informações foi de garantir a representação das alterações antrópicas no ambiente natural, com influência sobre o escoamento superficial da água.

O trabalho executado no ano de 2016 pela Terracap foi responsável pelo processo de classificação da nuvem de pontos e sua respectiva classificação temática. O processo de filtragem das informações em diferentes elementos temáticos (solo, vegetação, edificações, linhas de transmissão, dentre outros) foi realizado de forma automatizada e contando com a etapa de avaliação assistida dos resultados por parte dos técnicos envolvidos, garantindo a devida qualidade altimétrica das informações de terreno (TERRACAP, 2016). Assim, o presente estudo apenas utilizou os citados pontos altimétricos como dados de entrada para a estimativa do MDE.

No processo de interpolação, existem basicamente dois tipos de métodos, os determinísticos e os probabilísticos. Os primeiros partem de valores pré-definidos e parametrizações que são estimadas tendo por base as informações locais da amostra e, por sua vez, os probabilísticos consideram o comportamento estatístico das amostras como um todo para a parametrização do interpolador.

A interpolação dos dados utilizou o método do Inverso da Distância Ponderada (IDW), escolhido devido sua simplicidade e popularidade, sendo caracterizado como um método de interpolação determinístico

\begin{tabular}{llllll}
\hline Caminhos de Geografia & Uberlândia - MG & v. 22, n. 84 & dez/2021 & p. 301-322 & Página 305
\end{tabular}


que considera a influência de amostras vizinhas imediatas para a estimativa da altimetria, considerando formulações matemáticas (POLAT, UYSAL e TOPRAK, 2015). A Figura 3 mostra a área de estudo com parte da nuvem de pontos amostrais utilizados no processo de interpolação.

Segundo Lloyd e Atkinson (2002), os métodos de interpolação probabilísticos tendem a apresentar maior acurácia em áreas com menor densidade de pontos amostrais, mas concluíram que nenhum benefício é alcançado utilizando-se métodos sofisticados de interpolação em áreas com densa nuvem amostral proveniente do perfilamento à laser. Outros estudos nesse sentido podem ser consultados na literatura científica dentre os quais Yanalak (2003), Abramov e Mcewan (2004) e Bater e Coops (2009).

Considerando as particularidades das informações provenientes de sistemas LIDAR de aplicação topográfica, não existe uma definição ideal para a resolução espacial de um MDE, mas sim, um conjunto de soluções adequadas que devem ser utilizadas nessa estimativa, relacionadas à (i) conceitos cartográficos e estatísticos; (ii) poder de processamento do hardware; (iii) acurácia posicional; (iv) avaliação da densidade de pontos amostrais; (v) estrutura de autocorrelação espacial; e (vi) complexidade do terreno (JENSEN, 2011). Segundo Hengl (2006), a resolução espacial do modelo para esses casos deve ser, no máximo, a metade do espaçamento médio dos pares de amostras mais próximas. Neste sentido, adotou-se o valor de 0,2 metros como resolução espacial do modelo, uma vez que os dados altimétrico provenientes do LIDAR possuem uma densidade média de 4 pontos $/ \mathrm{m}^{2}$.

Após a elaboração do MDE, realizou-se o preenchimento das depressões espúrias visando garantir a devida conectividade da superfície do modelo. A Figura 4 apresenta o MDE elaborado e corrigido, bem como as localidades que sofreram a respectiva correção.

Figura 3 - Nuvem de pontos amostrais utilizadas para a geração do MDE.

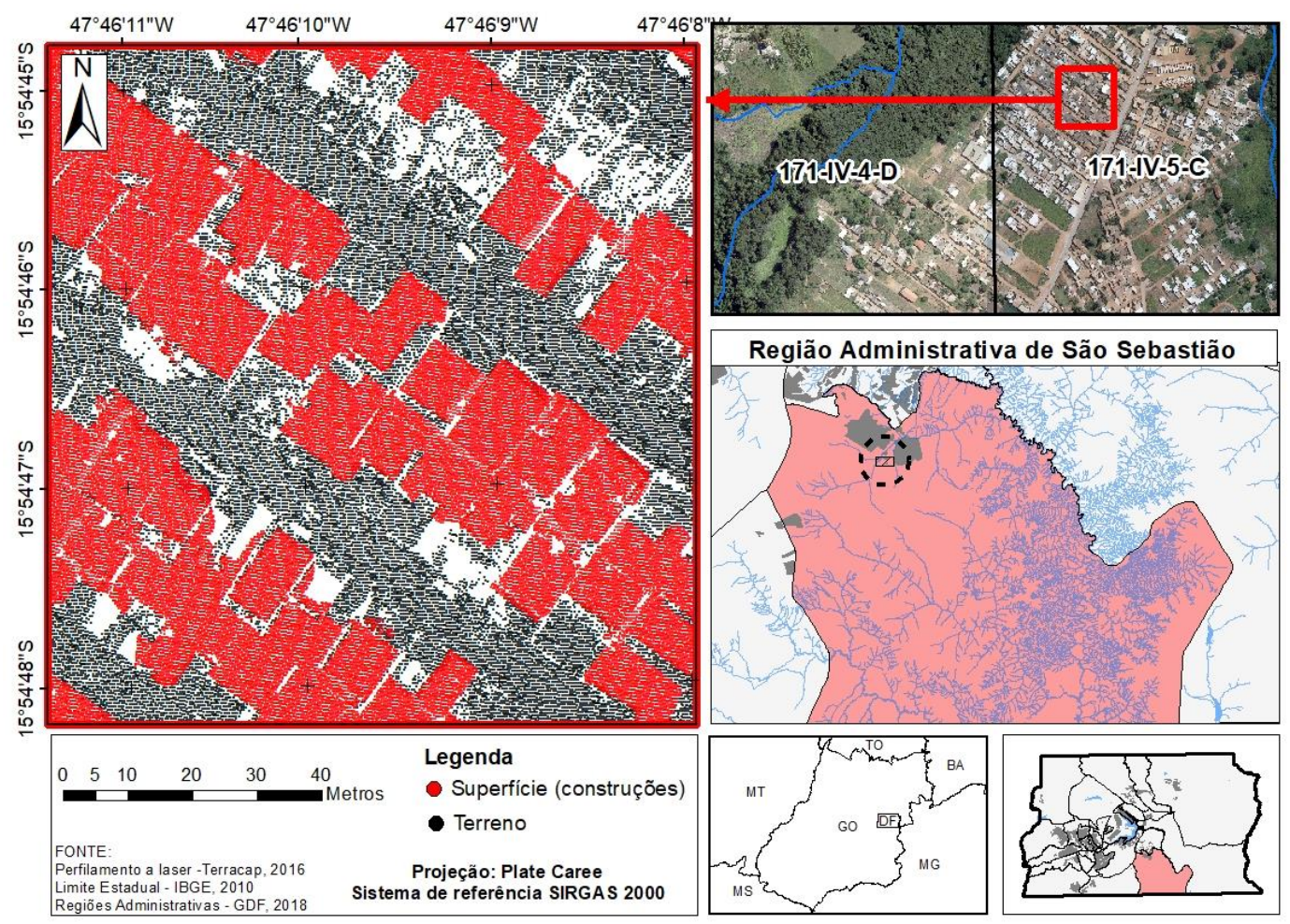

Fonte: Terracap, 2016; IBGE, 2010; GDF, 2018; Org. Autores 
Potencialidades e limitações do uso de informações altimétricas provenientes de perfilamento à laser em ambiente urbano
Felipe Lima Ramos Barbosa

Renato Fontes Guimarães

Osmar A. de Carvalho Júnior

Roberto A. Trancoso Gomes Erondina Azevedo de Lima

Figura 4 - Modelo Digital de Elevação (MDE) elaborado e corrigido e a localidade das depressões espúrias preenchidas.

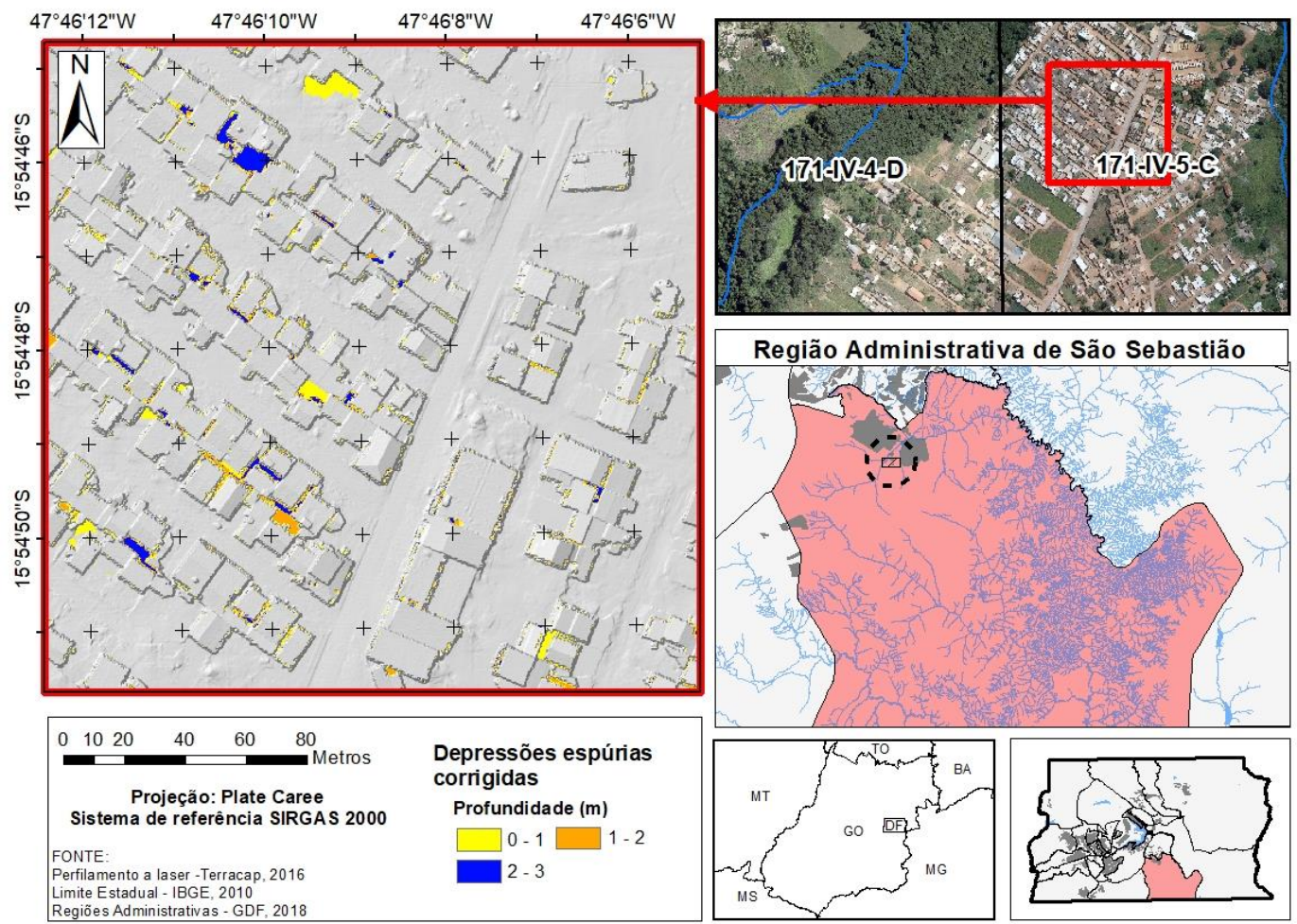

Fonte: Terracap, 2016; IBGE, 2010; GDF, 2018; Org. Autores

\section{Aplicação do índice ITU e delimitação das ASH}

Os atributos de terreno utilizados para o cálculo do ITU são: (i) a área de contribuição à montante; e (ii) a declividade local. A área de contribuição à montante foi obtida pelo método de estimativa de fluxo direcional (TARBOTON, 1997). Esse método utiliza um sistema proporcional que pondera o fluxo segundo o ângulo estabelecido entre o escoamento identificado e o caminho preferencial mais próximo a esse, simulando, assim, certa dispersão na modelagem. Uma vez estimado o fluxo direcional, calculase para cada pixel o somatório das áreas das células a montante que drenam diretamente para ele (WALLIS et al., 2009). O índice ITU foi processado no software Whitebox GAT (LINDSAY, 2016).

Para a estimativa das HSA adotou-se solução concebida por Thomas et al. (2017), que divide os valores do índice ITU em 100 classes de igual área e, subsequentemente, representa apenas os 15\% das regiões de maior propensão ao escoamento superficial do modelo. Portanto, o mapa ASH foi estratificado em três classes de porcentagens de área (5\%, 10\% e 15\%), valores escolhidos de forma aleatória, uma vez que o uso de múltiplos limiares reduz o erro de estimativa dos tamanhos das ASH (THOMAS et al., 2017). Assim, as ASH no presente estudo indicam o agregado dos $15 \%$ superiores da área de propensão ao escoamento superficial, considerando seus aspectos topográficos.

\section{RESULTADOS E DISCUSSÕES}

\section{Atributos de terreno}

A Figura 5 mostra o MDE corrigido e a respectiva área de contribuição à montante, no caso apresentada em função logarítmica para melhor visualização dos resultados. A declividade local da área de estudo foi calculada em graus (Figura 6). 
Potencialidades e limitações do uso de informações altimétricas provenientes de perfilamento à laser em ambiente urbano
Felipe Lima Ramos Barbosa

Renato Fontes Guimarães

Osmar A. de Carvalho Júnior

Roberto A. Trancoso Gomes Erondina Azevedo de Lima

Figura 5 - Apresenta o modelo de fluxo acumulado estimado para a área de estudo.
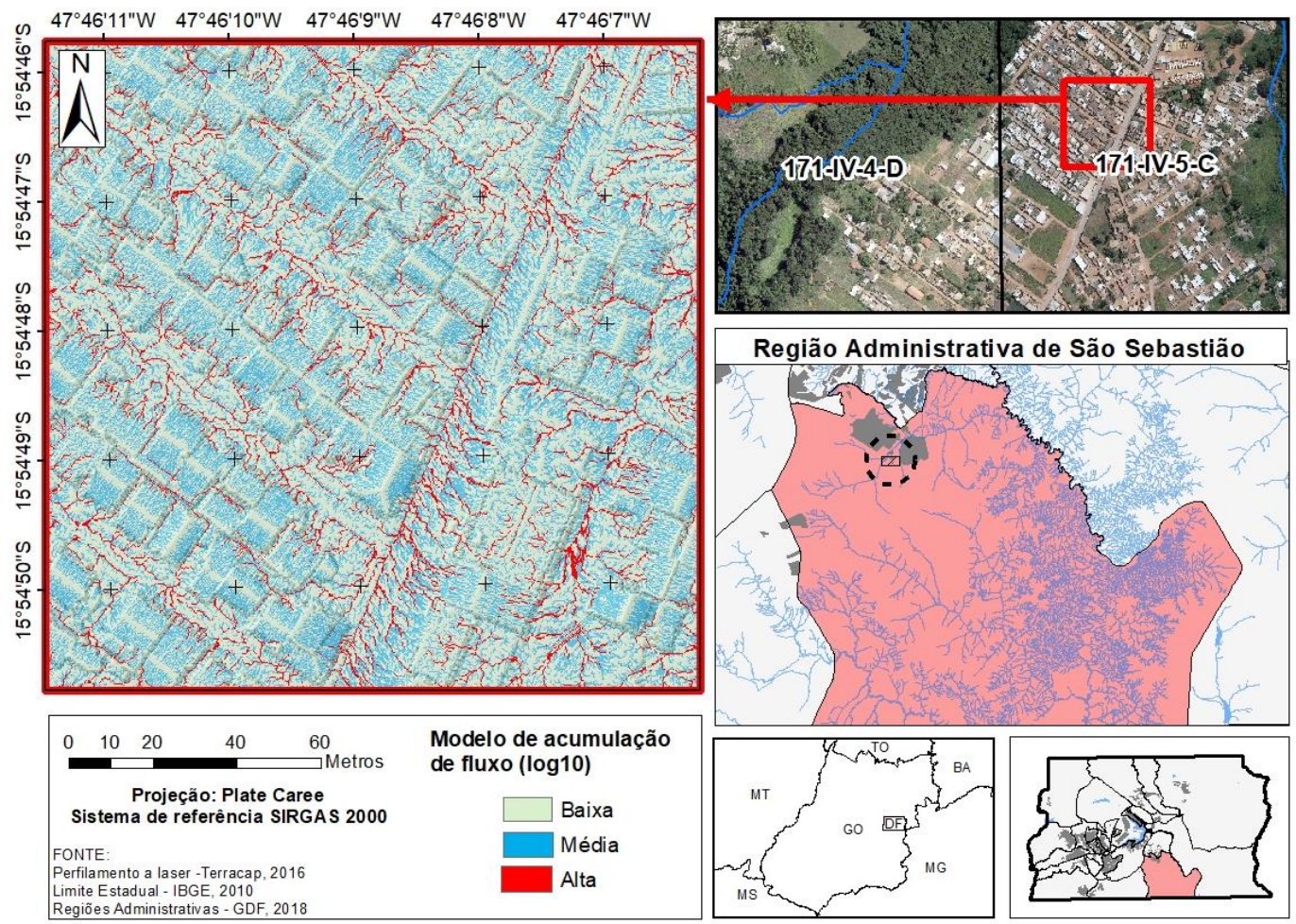

Fonte: Terracap, 2016; IBGE, 2010; GDF, 2018; Org. Autores

Figura 6 - Declividade local, estimada em graus, da área de estudo.
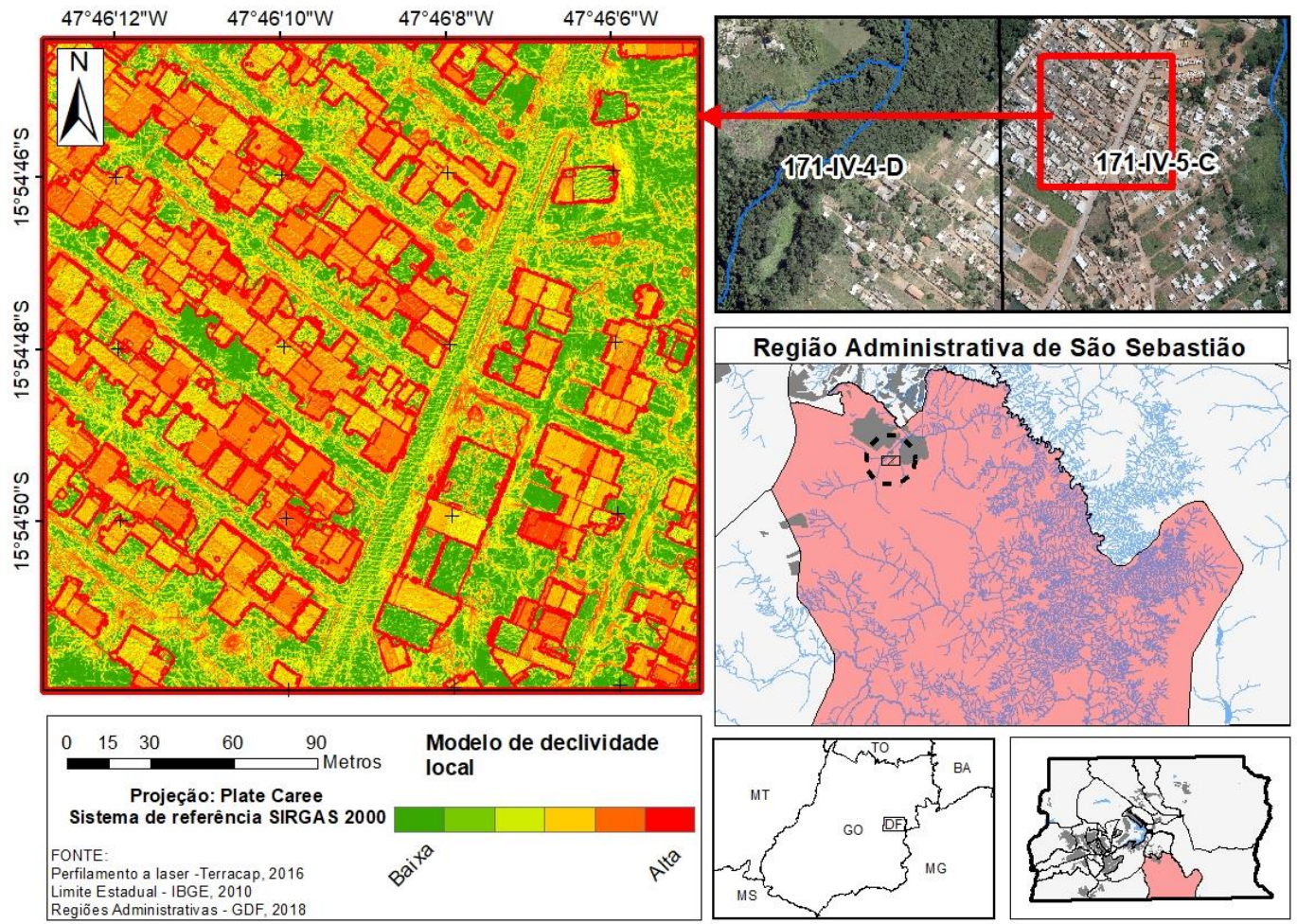

Fonte: Terracap, 2016; IBGE, 2010; GDF, 2018; Org. Autores

A Figura 7 mostra o histograma de frequências dos valores da área de contribuição em metros quadrados, representado na função log10, e a Tabela 1 apresenta os respectivos valores de média $\left(79,99 \mathrm{~m}^{2}\right)$, mediana $\left(0,15 \mathrm{~m}^{2}\right)$ e desvio padrão $-\sigma\left(2.339,92 \mathrm{~m}^{2}\right)$ da distribuição. Os resultados indicam Caminhos de Geografia Uberlândia - MG $\quad$ v. 22, n. $84 \quad$ dez/2021 p. 301-322 Página 308 
um comportamento assimétrico com acúmulo nos baixos valores da distribuição, o que pode ser constatado, principalmente, pelo valor encontrado de $0,15 \mathrm{~m}^{2}$ referente a mediana da distribuição, medida estatística que minimiza o efeito dos outliers na análise. Assumindo a distribuição normal dos dados, a um nível de confiança de 99,73\%, o limiar é de 7.019,76 $\mathrm{m}^{2}(3 \sigma)$, valor relativamente baixo de área de contribuição considerando a totalidade da área de estudo (Tabela 1). Os resultados ressaltam a influência da topografia local no comportamento superficial do escoamento de água devido a presença de objetos urbanos que funcionam como divisores d'água artificiais, ou mesmo como obstáculos, assim, reduzindo os valores de área de contribuição e afetando diretamente o índice ITU. Essas constatações também foram exploradas por outros estudos que analisaram os efeitos do uso de LIDAR DEM em aplicações hidrológicas (GILLIN et al., 2015; SORENSEN e SEIBERT, 2007; VAZE, TENG e SPENCER, 2010; THOMAS et al., 2017).

Tabela 1 - Valores de média, mediana e desvio padrão da área de contribuição.

\begin{tabular}{cc}
\hline Estatística descritiva & Valores $\left.\mathbf{( m}^{\mathbf{2}}\right)$ \\
\hline Média & 79,99 \\
Mediana & 0,15 \\
Desvio padrão & $2.339,92$ \\
\hline
\end{tabular}

Fonte: Org. Autores

Figura 7 - Apresenta porção da área de estudo, a estimativa de área de contribuição e sua distribuição de frequência.
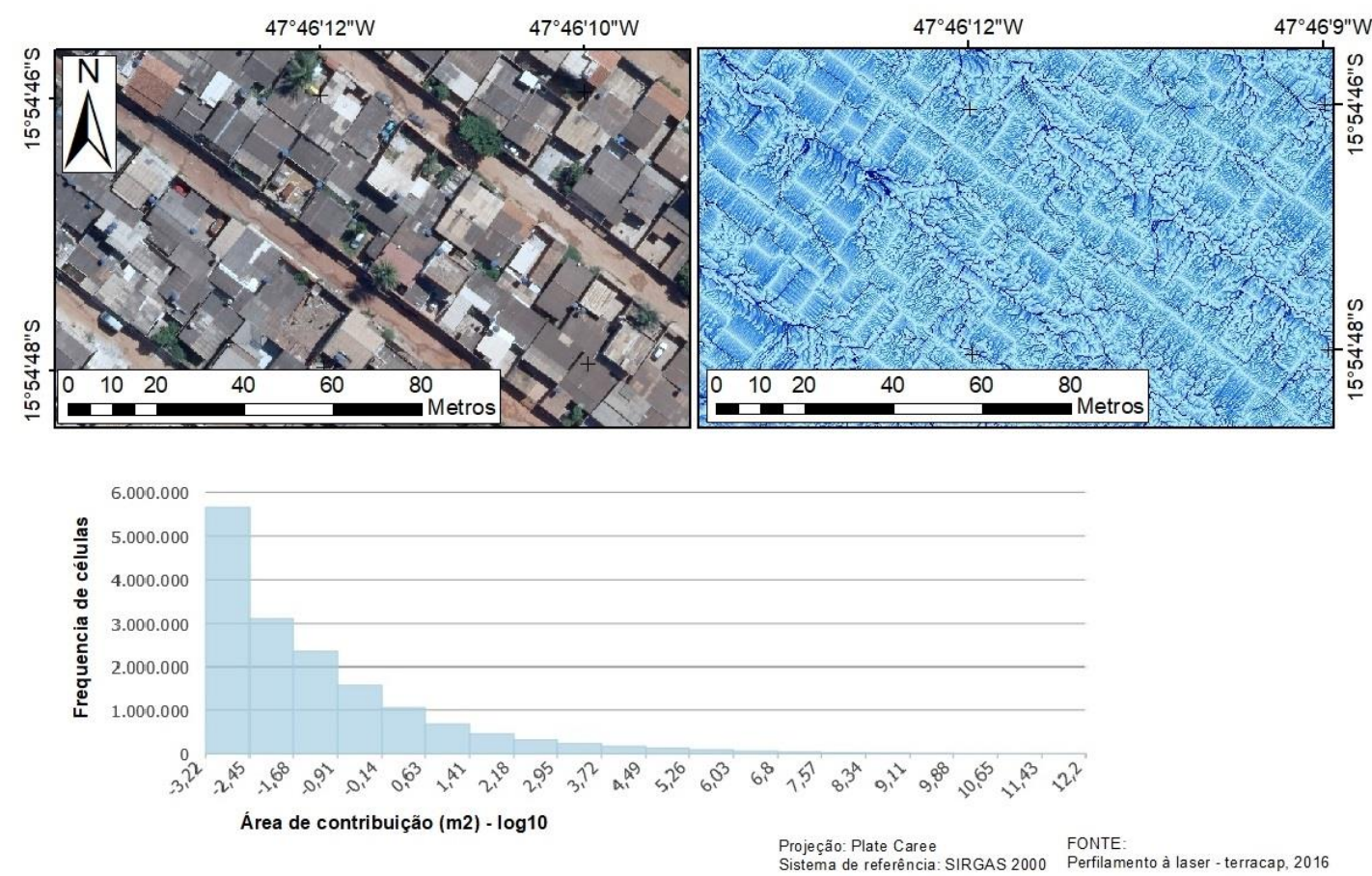

Fonte: Terracap, 2016; Org. Autores

A Figura 8 apresenta o índice ITU para a área de estudo, cujos resultados indicam uma baixa concentração de valores próximos às construções e objetos antrópicos no terreno, com concentração do fluxo em pontos específicos da área urbana, caracterizados por depressões e/ou barramentos artificiais que foram criados devido à alteração antrópica do ambiente, pontos estratégicos que merece atenção dos tomadores de decisão. 
Figura 8 - Índice ITU estimado para a área de estudo.

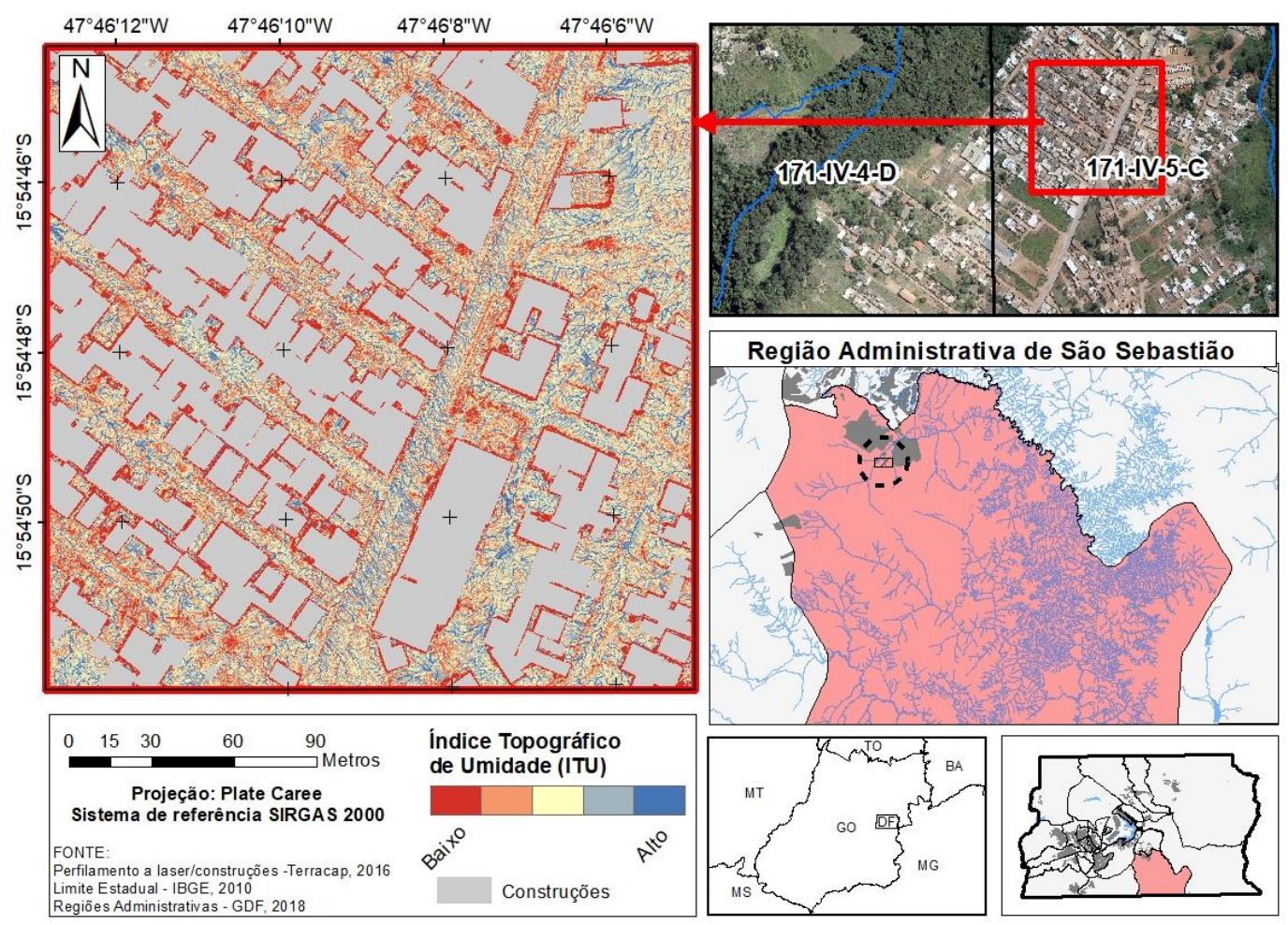

Fonte: Terracap, 2016; IBGE, 2010; GDF, 2018; Org. Autores

\section{Distribuição espacial das Áreas de Sensibilidade Hidrológica}

A estimativa das ASH é uma importante informação que auxilia o processo de planejamento e gestão do espaço urbano, que vêm, recentemente, passando por um processo de ocupação acelerado e não planejado. A Tabela 2 apresenta as áreas de cada uma das classes de ASH em relação à área total do estudo. A Figura 9 mostra a área de estudo com as respectivas classes de ASH estimadas.

Tabela 2 - Valores de área das classes de ASH em relação à área total do estudo

\begin{tabular}{cc}
\hline Porcentagem & Área $\left(\mathbf{m}^{2}\right)$ \\
\hline $5 \%$ & $32.187,50$ \\
$10 \%$ & $64.375,00$ \\
$15 \%$ & $96.562,50$ \\
\hline Total de área de estudo & $\mathbf{6 4 3 . 7 5 0 . 0 0}$ \\
\hline \multicolumn{2}{c}{ Fonte: Org. Autores }
\end{tabular}


Potencialidades e limitações do uso de informações altimétricas provenientes de perfilamento à laser em ambiente urbano
Felipe Lima Ramos Barbosa

Renato Fontes Guimarães

Osmar A. de Carvalho Júnior

Roberto A. Trancoso Gomes

Erondina Azevedo de Lima

Figura 9 - ASH estimadas na área de estudo.
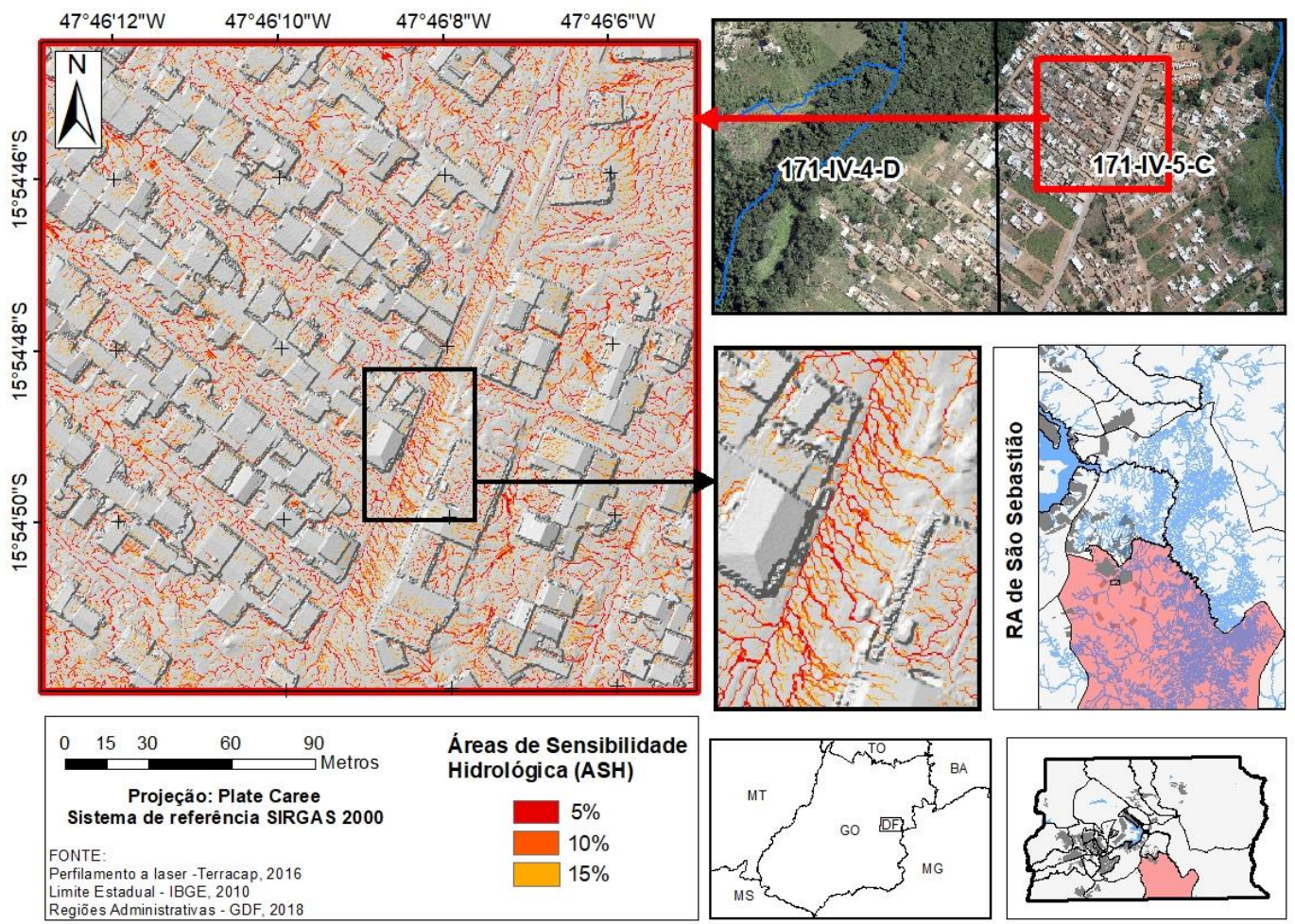

Fonte: Terracap, 2016; IBGE, 2010; GDF, 2018; Org. Autores

A Figura 10 apresenta uma porção da área de estudo com a ortofoto e as respectivas ASH estimadas, onde observa-se uma coerência entre a inferência das ASH e o escoamento superficial. A malha urbana local influência no direcionamento do escoamento superficial da água mesmo com arruamentos não pavimentados, potencializando os impactos ambientais e sociais na região, tais como assoreamentos, erosões e inundações.

Figura 10 - Porção da área de estudo representada com sua ortofoto e as respectivas ASH inferidas.

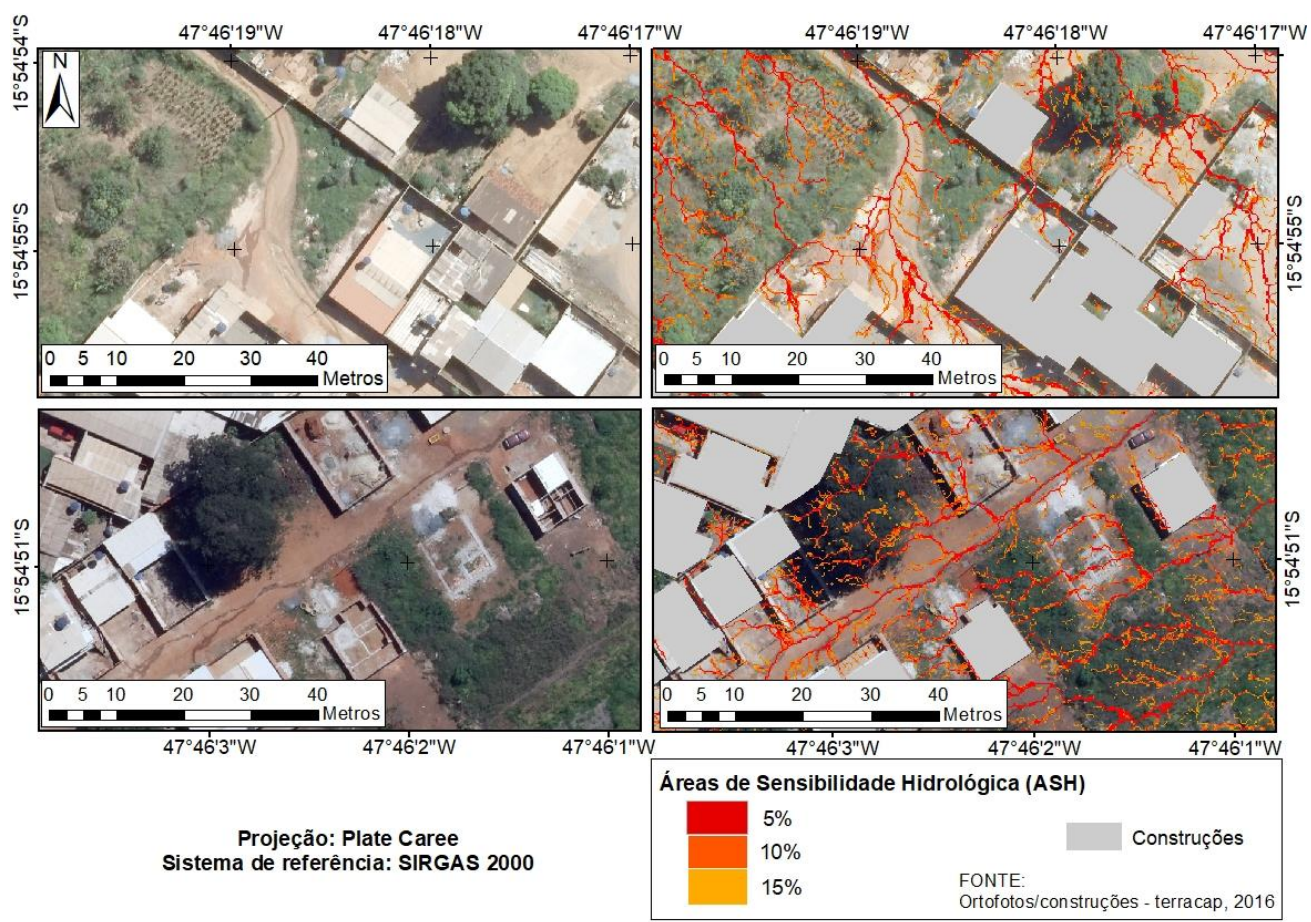


Potencialidades e limitações do uso de informações altimétricas provenientes de perfilamento à laser em ambiente urbano
Felipe Lima Ramos Barbosa

Renato Fontes Guimarães

Osmar A. de Carvalho Júnior

Roberto A. Trancoso Gomes Erondina Azevedo de Lima

\section{Fonte: Terracap, 2016; Org. Autores}

A Tabela 3 apresenta as estatísticas das ASH considerando os valores de declividade, área de contribuição e ITU. De forma geral, observam-se baixos valores de declividade, cujas médias variam de 3,02 a 3,51 graus, com $\sigma$ entre 3,86 a 4,7, o que indicam áreas relativamente planas em locais com maior propensão ao escoamento superficial. $O$ agrupamento assimétrico dos resultados junto a elevada amplitude máxima (74 - 83 graus) indicam poucas áreas com elevada declividade, essas associadas a muros e casas que apresentam elevada variação altimétrica em um MDE de alta resolução espacial. Os resultados referentes as áreas de contribuição das ASH também indicam a alta influência da topografia local. As diferenças encontradas entre os valores de média $\left(1.638,1-576,5 \mathrm{~m}^{2}\right)$ e mediana $\left(86,5-8,1 \mathrm{~m}^{2}\right)$ ressaltam uma distribuição assimétrica dos resultados e indicam uma alta frequência de baixos valores, com presença de outliers elevados $\left(\sigma-10.558,3\right.$ a $\left.6.280,7 \mathrm{~m}^{2}\right)$. Ademais, os valores estatísticos são decrescentes entre as classes de $\mathrm{ASH}$, o que indica o aumento da influência de obstáculos naturais ou artificiais na estimativa dos caminhos de fluxo superficial, tendência também observada na Tabela 1. As distribuições dos valores de ITU se mostraram simétricos, com valores aproximados de média e mediana e baixos valores de $\sigma$. Esses resultados ressaltam a escolha quanto a definição das ASH sobre o ITU, que considerou valores limiares entre classes tendo por base iguais áreas. Segundo Thomas et al., (2017), os mapas de ITU derivados de MDE LIDAR predominantemente capturam a influência das feições de microtopografia na modelagem hidrológica.

Tabela 3 - Valores estatísticos das ASH.

\begin{tabular}{|c|c|c|c|c|c|c|c|c|c|c|c|c|c|c|c|}
\hline \multirow{2}{*}{ ASH } & \multicolumn{5}{|c|}{ Declividade (graus) } & \multicolumn{5}{|c|}{ Área de contribuição $\left(\mathrm{m}^{2}\right)$} & \multicolumn{5}{|c|}{ Índice Topográfico de Umidade } \\
\hline & $\mathbf{M}$ & Med & DP & $\mathbf{i}$ & $\mathbf{I}$ & $\mathbf{M}$ & Med & DP & $\mathbf{i}$ & I & M & Med & DP & $\mathbf{i}$ & I \\
\hline $5 \%$ & 3,0 & 1,9 & 3,8 & 0 & 74 & $1.638,1$ & 86,5 & $10.558,3$ & 0 & 198.020 & 9,7 & 9,3 & 1,8 & 7,5 & 20,6 \\
\hline $10 \%$ & 3,3 & 2,1 & 4,3 & 0 & 82 & 848,3 & 20,4 & 7.612 .2 & 0 & 198.020 & 8,3 & 7,7 & 2 & 5,8 & 20,6 \\
\hline $15 \%$ & 3,5 & 2,2 & 4,7 & 0 & 83 & 576,5 & 8,1 & $6.280,7$ & 0 & 198.020 & 7,4 & 6,8 & 2,1 & 4,9 & 20,6 \\
\hline
\end{tabular}

M - Média/ Med - Mediana/ DP - Desvio padrão/ i - Mínimo/ I - Máximo

Fonte: Org. Autores

A Figura 11 evidencia a influência da malha urbana sobre o escoamento superficial da água e das ASH em diferentes contextos, destacados por círculos na cor roxo, tendo em vista a elevada variação altimétrica introduzida pela existência de artefatos artificiais (muros, telhados, barreiras, entre outros). São destacadas, ainda, por círculos amarelos as áreas de comportamento natural. Apesar das potencialidades inerentes ao uso de dados altimétricos provenientes de perfilamento à laser (Figura 10), algumas limitações necessitam ser ressaltadas.

Figura 11 - Porção da área de estudo com influência da malha de arruamentos sobre as ASH. 
Potencialidades e limitações do uso de informações altimétricas provenientes de perfilamento à laser em ambiente urbano
Felipe Lima Ramos Barbosa

Renato Fontes Guimarães Osmar A. de Carvalho Júnior Roberto A. Trancoso Gomes Erondina Azevedo de Lima

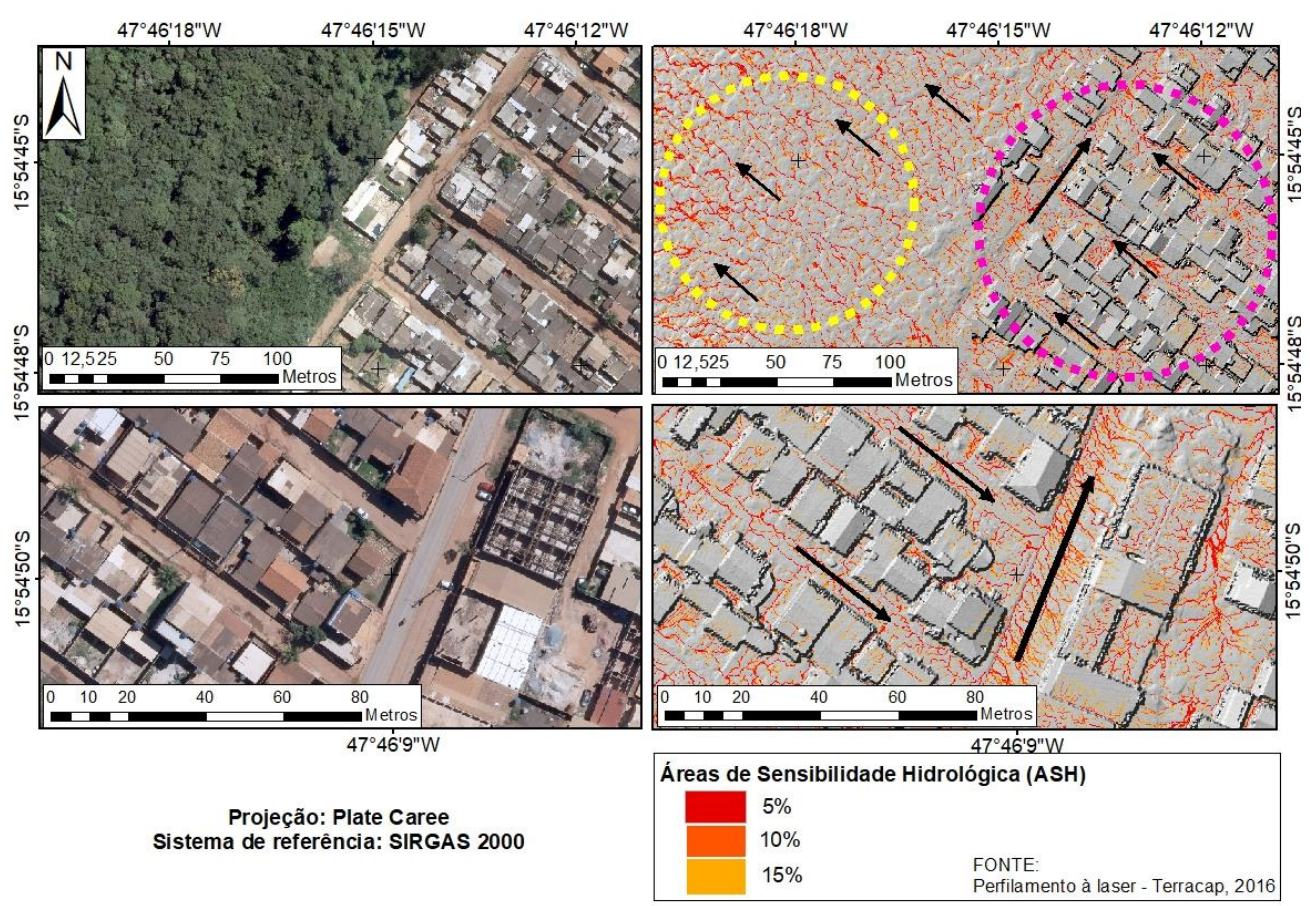

Fonte: Terracap, 2016; Org. Autores

\section{A interferência da cobertura vegetal}

A depender da estrutura do dossel e de seus subdosséis, o feixe de laser não consegue registrar com exatidão informações de terreno, o que prejudica as inferências que podem ser extraídas desses produtos. A Figura 12 apresenta áreas de sofreram ajuste altimétrico durante o processo de modelagem, o que influencia diretamente o comportamento do escoamento superficial, indicadas por círculos na cor azul.

Figura 12 - Exemplos de inconsistência introduzida na modelagem devido à densidade da cobertura vegetal.

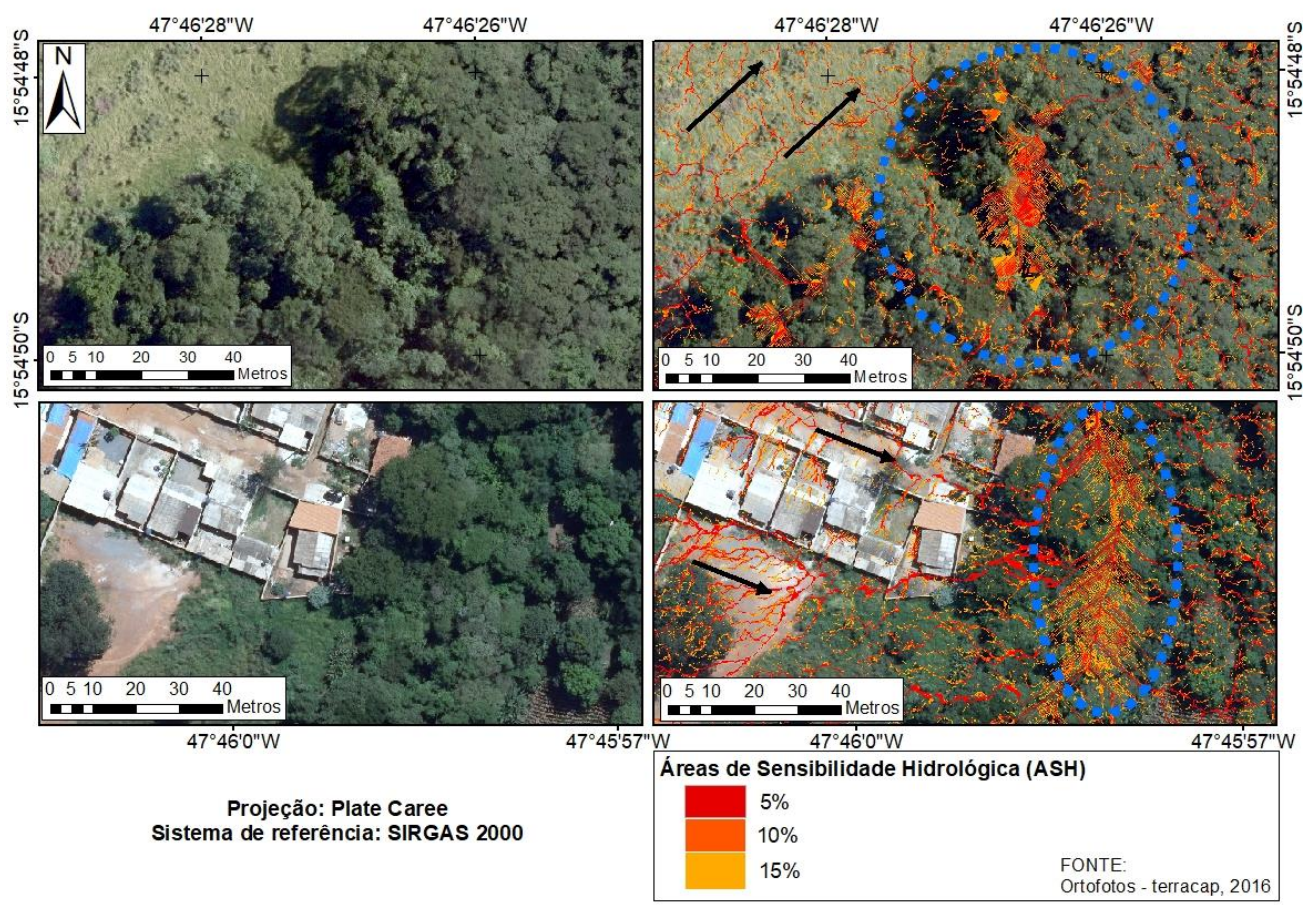

Fonte: Terracap, 2016; Org. Autores 
Potencialidades e limitações do uso de informações altimétricas provenientes de perfilamento à laser em ambiente urbano
Felipe Lima Ramos Barbosa

Renato Fontes Guimarães Osmar A. de Carvalho Júnior

Roberto A. Trancoso Gomes Erondina Azevedo de Lima

Percebe-se que as áreas que apresentaram maior alteração altimétrica devido o preenchimento de depressões espúrias resultaram na diminuição dos valores de declividade, fato que influenciou diretamente a definição das ASH. A Figura 13 apresenta um exemplo dessa relação e seu efeito no mapeamento das ASH. 
Figura 13 - Exemplo da relação entre declividade, depressão espúria preenchida e ASH em área de vegetação.

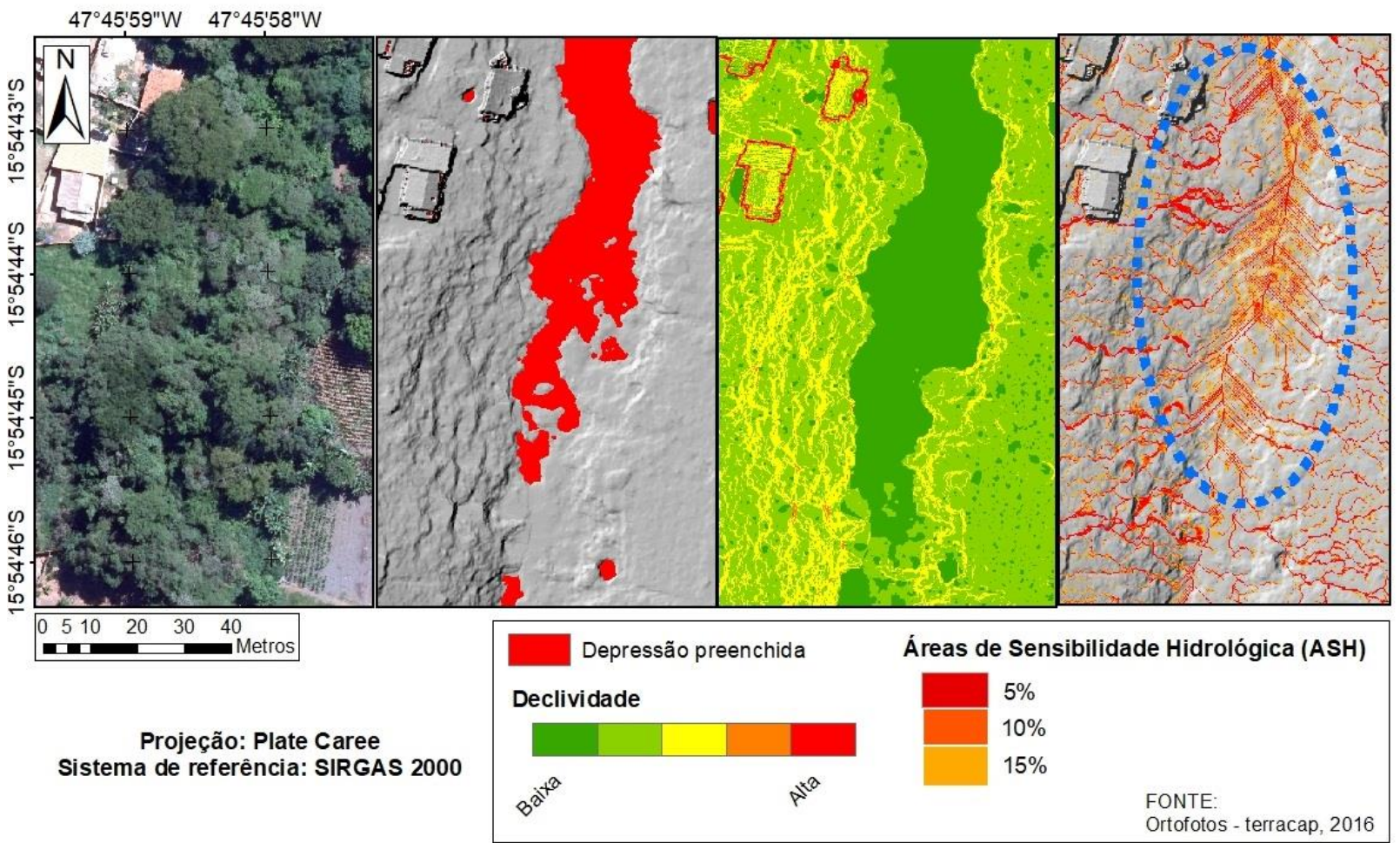

Fonte: Terracap, 2016; Org. Autores

O preenchimento das depressões espúrias ocorreu no processo de modelagem uma vez que a variação das diferentes coberturas de vegetação tem impacto direto na densidade de pontos inferidos como respostas de terreno provenientes dos feixes ópticos emitidos pelo sistema LIDAR. Coberturas de vegetação entre 80 a $90 \%$ da área amostrada podem resultar em apenas $10 \%$ de respostas de terreno, sendo que neste montante, ainda pode-se identificar "falsos positivos" (COWEN et al., 2000). Segundo Hutson (2015), o tipo de dossel da vegetação parece provocar maior limitação do que sua altura. Mesmo em locais onde se observa uma densa e alta vegetação, pode-se ter bons retornos de solo quando não existem dosséis intermediários entre a vegetação e o terreno. Por outro lado, coberturas de vegetação do tipo arbustivas parecem resultar em uma diminuição do retorno relacionado ao solo, provavelmente vinculados a confusão intra-dossel típicas desse tipo de vegetação, que apresentam baixa variabilidade altimétrica entre seus indivíduos. Resultados nesse sentido foram verificados em diversos estudos científicos que tiveram o caráter de avaliar dados provenientes de sistemas LIDAR visando diversificadas aplicações (HODGSON et al., 2003; CROW et al., 2007; DONEUS et al., 2008; BRUBAKER et al., 2013; HUTSON, 2015).

Percebe-se que a cobertura vegetal é uma questão crítica que deve ser considerada não só nos levantamentos topográficos provenientes de perfilamento à laser, mas em qualquer uso de tecnologia ativa de coleta de dados. As informações confiáveis são provenientes apenas de objetos que interagiram diretamente com o método de coleta. Nas demais áreas de oclusão, as informações altimétricas de terreno acabam sendo estimadas a partir de diferentes técnicas de filtragem, no caso da tecnologia LIDAR, ou mesmo o uso das convencionais técnicas de fotogrametria, fato que acrescenta incerteza nas medições realizadas.

Segundo Pfeifer, Gorte e Elberink (2004), a limitação relacionada à densidade de cobertura vegetal não pode ser resolvida com o uso de sistemas convencionais de perfilamento à laser, o que abre um campo novo de discussões a respeito da utilização de sistemas LIDAR que registram todo o comprimento de onda emitido, diferente do sistema discreto apresentado acima, no melhoramento da identificação de retornos de solo em situações de vegetação arbustiva (CROW et al., 2007).

Neste sentido, e tendo por finalidade minimizar ou controlar as incertezas, a utilização de técnicas de fotogrametria conjugadas com as de perfilamento à laser podem ser uma potencialidade visando 
Potencialidades e limitações do uso de informações altimétricas provenientes de perfilamento à laser em ambiente urbano

garantir uma melhor qualidade na derivação de informações altimétricas, tais como curvas de nível, hidrografia e pontos cotados, bem como na geração de MDE.

\section{$O$ efeito da topografia local}

Uma limitação do uso de dados LIDAR em aplicações topográficas está principalmente relacionada à influência da topografia local sobre os dados originais, prejudicando estimativas de escoamento superficial.

Segundo Thomas et al. (2017), a definição da resolução espacial do MDE deve considerar a sua aplicação, mesmo que os dados de entrada permitam um melhor refinamento. Essa argumentação vem da constatação de que, por um lado, modelos muito grosseiros podem generalizar em demasia informações primordiais referentes ao comportamento e controle topográfico da região. E, por outro, modelos com elevada resolução espacial podem favorecer a influência da topografia local nas inferências espaciais, essas que, muitas vezes, não estão relacionadas diretamente ao controle exercido pelo relevo sob o comportamento mais regionalizado do escoamento superficial da água. Diversos estudos na literatura constataram a influência da resolução espacial do MDE nos atributos topográficos (declividade, aspecto, área de contribuição à montante, dentre outros). Segundo Gillin et al. (2015), a resolução espacial deve ser estabelecida considerando um balanço entre os efeitos dos fatores regionais que realizam o controle topográfico e a influência desejada, ou não, da topografia local sobre o modelo.

Segundo Carvalho Júnior et al. (2010) e Freitas et al. (2012), um MDE urbano que represente a geometria individual de prédios, blocos e arruamentos permite uma melhor descrição do escoamento superficial da água, as alterações dos fluxos causadas pelas rápidas mudanças morfológicas do ambiente e seu consequente efeito sobre os processos de erosão.

\section{Análise comparativa com estudos de detecção de ASH em regiões urbanas}

Os estudos científicos relacionados à identificação das ASH utilizando sistemas LIDAR e o índice ITU estão focados, principalmente, em aplicações agrícolas e em escala regional. Dentre eles, destaca-se o trabalho de Thomas et al. (2016) que desenvolveram uma metodologia para identificar com acurácia as áreas críticas relacionadas à poluição difusa em duas bacias hidrográficas na Irlanda com uso agrícola utilizando LIDAR MDE. Agnew et al. (2006) desenvolveram um estudo visando analisar a performance do índice ITU, adaptado com informações relativas à condutividade hidráulica do solo saturado e sua profundidade, na estimativa das ASH em diferentes contextos agrícolas. Segundo os autores, foi constatado consistente correlação entre as estimativas provenientes do índice ITU e a probabilidade de saturação do solo, fato que auxilia a identificação de áreas críticas quando sobrepostas aos diversos padrões de uso e ocupação da terra.

A identificação das ASH também é objeto de pesquisas realizadas em escala regional, cujas metodologias referentes à sua estimativa variam a depender de cada particularidade, sendo que o ambiente urbano se resume, basicamente, a uma das diversas classes temáticas do uso e ocupação da terra. Wu, Giri e Qiu (2016) analisaram a delimitação das ASH em três diferentes cenários de uso e ocupação da terra e, apesar de não lidar diretamente com o ambiente urbano, seu resultado indica que a estimativa de ASH aumentou em áreas de intenso uso e ocupação da terra, tais como às agrícolas e a urbana. Resultados semelhantes também foram alcançados por Giri, Qiu e Zhang (2017), ao lidar com variações na parametrização da estimativa do índice topográfico de solo visando a estimativa das ASH em diferentes classes de uso e ocupação da terra, na escala de bacia hidrográfica. Qiu et al. (2019) avaliaram o relacionamento entre as alterações do uso e ocupação da terra e a degradação dos ecossistemas aquáticos a partir da perspectiva de $\mathrm{ASH}$, e concluíram que quanto maior a intensidade do grau de urbanização de uma bacia hidrográfica, maior os impactos observados na estimativa das ASH. Os resultados apresentados por tais autores também foram realizados na escala de análise de bacia hidrográfica.

Nesse contexto, a presente pesquisa inova ao adaptar a metodologia para a identificação das ASH a partir do índice ITU em ambientes restritamente urbanos em escala local. Devido à alta acurácia relativa ao relevo extraído de sistema LIDAR foi possível considerar os diferentes arranjos de ruas e edificações do ambiente intraurbano na delimitação das ASH. A abordagem proposta apresenta significativa contribuição uma vez que permite a rápida identificação das $A S H$, informação de grande valia aos tomadores de decisão na definição das melhores estratégicas de intervenção urbana.

\begin{tabular}{llllll}
\hline Caminhos de Geografia & Uberlândia - MG & v. 22, n. 84 & dez/2021 & p. 301-322 & Página 316
\end{tabular}


Potencialidades e limitações do uso de informações altimétricas provenientes de perfilamento à laser em ambiente urbano
Felipe Lima Ramos Barbosa

Renato Fontes Guimarães Osmar A. de Carvalho Júnior

Roberto A. Trancoso Gomes Erondina Azevedo de Lima 


\section{CONSIDERAÇÕES FINAIS}

A presente pesquisa apresenta uma abordagem metodológica de estimativa das ASH em escala local no ambiente urbano, baseada em intervalos do índice ITU. Com a tecnologia LIDAR, é possível representar o relevo em alta resolução espacial a partir da utilização de informações altimétricas de alta precisão. O uso dessa tecnologia potencializa o monitoramento de áreas urbanas, uma vez que permite a inferência dos artefatos relacionados à topografia local, importantes para algumas aplicações relacionadas à previsão de possíveis impactos ambientais, bem como na área da engenharia e do planejamento urbano.

A influência dos objetos urbanos no MDE pôde ser constatada, inicialmente, pela diferença encontrada entre os valores de média $\left(79,99 \mathrm{~m}^{2}\right)$, mediana $\left(0,15 \mathrm{~m}^{2}\right)$ e de desvio padrão $\left(2.339,92 \mathrm{~m}^{2}\right)$ relativos à distribuição dos valores de área de contribuição em toda a região de estudo. Esse efeito foi também observado na análise dos resultados do mapeamento das ASH, especialmente considerando a distribuição dos valores de declividade e da área de contribuição. Em linhas gerais, a área de estudo apresenta distribuição assimétrica da declividade, o que indica uma região marcada por baixo gradiente de declividade (3,02 a 3,51 graus) e com a forte influência desses artefatos artificiais, esses que apresentam elevada variação altimétrica em um MDE LIDAR e ocasionam o registro de áreas pontuais com elevada declividade. Por sua vez, os resultados da distribuição da área de contribuição das ASH também indicam a influência urbana no MDE, cujos valores de média $\left(1.638,1-576,5 \mathrm{~m}^{2}\right)$ e mediana $\left(86,5-8,1 \mathrm{~m}^{2}\right)$ ressaltam uma distribuição assimétrica e indicam uma alta frequência de baixos valores, com presença de outliers elevados ( $\sigma-10.558,3$ a $\left.6.280,7 \mathrm{~m}^{2}\right)$.

Assim, a depender da finalidade, a expressiva influência dos objetos urbanos nos MDE LIDAR pode ser um obstáculo para a estimativa da convergência do fluxo de água em uma perspectiva mais regional. Nesta escala de trabalho, é necessário garantir um balanço entre a influência da microtopografia no escoamento superficial e a convergência e conectividade de fluxo a montante, o que requer uma reamostragem do MDE LIDAR para resoluções maiores.

Neste sentido, se faz necessário o aperfeiçoamento de uma metodologia específica que contorne, ou suavize, a influência dos artefatos inerente aos dados LIDAR, especificamente considerando as resoluções espaciais indicadas para a estimativa das $\mathrm{ASH}$ em escala regional, os procedimentos de filtragem das informações de terreno, as influências da redução da nuvem de pontos amostrais no processo de interpolação e geração do MDE e a incorporação das propriedades hidrológicas de solo na estimativa das $\mathrm{ASH}$, uma vez que o método utilizado na presente pesquisa considerou apenas o controle topográfico.

Ademais, observou-se a influência direta da cobertura vegetal na densidade de pontos amostrais LIDAR, o que ocasionou uma perda de qualidade do MDE gerado nessas áreas e, subsequentemente, a necessidade de preenchimento de depressões visando garantir o escoamento do fluxo no modelo. Esse efeito rebaixou a declividade e influenciou diretamente o traçado das ASH no terreno.

A metodologia permitiu identificar os padrões locais da ocorrência de ASH no ambiente urbano da região administrativa de São Sebastião. Os resultados alcançados indicam que o processo de urbanização sem planejamento altera o escoamento superficial de água, um dos principais fatores topográficos que influencia em inundações e erosões, ao direcionar e concentrar os fluxos em pontos críticos do terreno.

\section{AGRADECIMENTOS}

Os autores agradecem o apoio da Terracap no fornecimento da base cartográfica, especificamente 0 perfilamento à laser, utilizada no presente estudo. Os autores agradecem também ao Conselho Nacional de Desenvolvimento Científico e Tecnológico (CNPq) e à Fundação de Apoio e Pesquisa do Distrito Federal (FAP/DF).

\section{REFERÊNCIAS}

ABRAMOV, O.; MCEWAN, A. An evaluation of interpolation methods for Mars Orbiter Laser Altimeter (MOLA) data. International Journal of Remote Sensing, n. 25, v. 3, p. 669-676, 2004. https://doi.org/10.1080/01431160310001599006

$\begin{array}{llllll}\text { Caminhos de Geografia } & \text { Uberlândia - MG } & \text { v. 22, n. } 84 & \text { dez/2021 } & \text { p. 301-322 } & \text { Página } 318\end{array}$


Potencialidades e limitações do uso de informações altimétricas provenientes de perfilamento à laser em ambiente urbano
Felipe Lima Ramos Barbosa Renato Fontes Guimarães Osmar A. de Carvalho Júnior Roberto A. Trancoso Gomes Erondina Azevedo de Lima

AGNEW, L. J.; LYON, S.; GERARD-MARCHANT, P.; COLLINS, V. B.; LEMBO, A. J.; STEENHUIS, T. S.; WALTER, M. T. Identifying hydrologically sensitive areas: Bridging the gap between science and application. Journal of Environmental Management, v. 78, p. 63 - 76, 2006. http://doi.org/10.1016/i.jenvman.2005.04.021

ANA - Agência Nacional de Águas. Conjuntura dos recursos hídricos no Brasil: Informes 2016. Brasília, 2016. Disponível em: <http://www3.snirh.gov.br/portal/snirh/centrais-deconteudos/conjuntura-dos-recursos-hidricos/informe-conjuntura-2016.pdf/view>. Acesso em: 21 maio 2020.

BALTSAVIAS, E. P. Airborne Laser Scanning: Basic Relations and Formulas. Journal of Photogrammetry and Remote Sensing, v. 54, p. 199 - 214, 1999. Disponível em:

<http://www2.geog.ucl.ac.uk/ mdisney/teaching/teachingNEW/PPRS/papers/Baltsavias Lidar.pdf>. Acesso em: 05 jul. 2020.

BATER, C. W.; COOPS, N. C. Evaluating error associated with lidar-derived DEM interpolation. Computers \& Geosciences, v. 35, p. 289 - 300, 2009. https://doi.org/10.1016/..cageo.2008.09.001 BEVEN, K. J; KIRKBY, M. J. A Physically Based, Variable Contributing Area Model of Basin Hydrology. Bulletin of Hydrological Sciences, v. 24, p. $43-69,1979$. https://doi.org/10.1080/02626667909491834

BRUBAKER, K. M.; MYERS, W. L.; DROHAN, P. J.; MILLER, D. A.; BOYER, E. W. The Use of Lidar Terrain Data in Characterizing Surface Roughness and Microtopography. Applied and Environmental Soil Science, v. 2013, p. 1 - 14, 2013. http://dx.doi.org/10.1155/2013/891534 CARVALHO JÚNIOR, O. A.; GUIMARÃES, R.; FREITAS, L.; GOMES-LOEBMANN, D.; GOMES, R. A.; MARTINS, E.; MONTGOMERY, D. R. Urbanization impacts upon catchment hydrology and gully development using multi-temporal digital elevation data analysis. Earth Surface Processes and Landforms: The Journal of the British Geomorphological Research Group, v. 35, n. 5, p. 611 617, 2010. https://doi.org/10.1002/esp.1917

COSTA-CABRAL, M.; BURGES, S. J. Digital elevation model networks (DEMON): A model of flow over hillslopes for computation of contributing and dispersal areas. Water Resource Res., v. 30, n. 6, p. 1681 - 1692, 1994. https://doi.org/10.1029/93WR03512

COWEN, D. J.; JENSEN, J. R.; HENDRIX, C.; HODGSON, M. E.; SCHILL, S. R. A GIS-assisted rail construction econometric model that incorporates LIDAR data. Photogrammetric Engineering and Remote Sensing, v. 66, n. 11, p. 1323 - 1326, 2000. Disponível em:

<http://citeseerx.ist.psu.edu/viewdoc/download?doi=10.1.1.500.5511\&rep=rep1\&type=pdf $>$. Acesso em: 12 jul. 2020.

CROW, P.; BENHAM, S.; DEVEREUX, B. J.; AMABLE, G. S. Woodland vegetation and its implications for archaeological survey using LiDAR. Forestry, v. 80, n. 3, p. $241-252,2007$. https://doi.org/10.1093/forestry/cpm018

DONEUS, M.; BRIESE, C.; FERA, M.; JANNER, M. Archaeological prospection of forested areas using full-waveform airborne laser scanning. Journal of Archaeological Science, v. 35, n. 4, p. $882-$ 893, 2008. https://doi.org/10.1016/i.jas.2007.06.013

ESRI - Environmental Systems Research Institute. Archydro 10.8 [S.I.]: ESRI, 2020. Disponível em $<$ http://downloads.esri.com/archydro/archydro/> [programa de computador]. Acesso em: 01 maio 2020.

FREITAS, L. F.; GUIMARÃES, R. F; CARVALHO JÚNIOR, O. A.; GOMES, R. A. T. Relacionamento entre a mudança da rede de drenagem devido à construção de estruturas urbanas e o surgimento de voçorocas e ravinas no bairro do Jardim Botânico no Distrito Federal. Revista Brasileira de Geomorfologia, v. 13, n. 4, p. 419 - 433, 2012. http://dx.doi.org/10.20502/rbg.v13i4.294 GDF - Governo do Distrito Federal. Zoneamento Ecológico-Econômico do Distrito Federal (ZEE/DF). Brasília, 2018. Disponível em: <http://zee.df.gov.br/>. Acesso em: 10 de junho de 2020. GILLIN, C. P.; BAILEY, S. W.; MCGUIRE, K. J.; PRISLEY, S. P. Evaluation of Lidar-derived DEMs through Terrain Analysis and Field Comparison. Photogrammetric Engineering \& Remote Sensing, v. 81 , n. 5, p. $387-396,2015$. https://doi.org/10.14358/PERS.81.5.387

$\begin{array}{llllll}\text { Caminhos de Geografia } & \text { Uberlândia - MG } & \text { v. 22, n. } 84 & \text { dez/2021 } & \text { p. 301-322 } & \text { Página } 319\end{array}$


Potencialidades e limitações do uso de informações altimétricas provenientes de perfilamento à laser em ambiente urbano
Felipe Lima Ramos Barbosa Renato Fontes Guimarães Osmar A. de Carvalho Júnior Roberto A. Trancoso Gomes Erondina Azevedo de Lima

GIONGO, M.; KOEHLER, H. S.; MACHADO, S. A.; KIRCHNER, F. F.; MARCHETTI, M. LIDAR: princípios e aplicações florestais. Pesquisa Florestal Brasileira, v. 30, n. 63, p. 231 - 244, 2010. https://doi.org/10.4336/2010.pfb.30.63.231

GIRI, S.; QIU, Z.; ZHANG, Z. A novel technique for establishing soil topographic index thresholds in defining hydrologically sensitive areas in landscapes. Journal of Environmental Management, $v$. 200, p. 391 - 399, 2017. https://doi.org/10.1016/j.jenvman.2017.04.080

GRABS, T.; SEIBERT, J.; BISHOP, K.; LAUDON, H. Modelling spatial patterns of saturated areas: A comparison of the topographic wetness index and a dynamic distributed model. Journal of Hydrology, v. 373, n. 1 - 2, p. 15 - 23, 2009. https://doi.org/10.1016/j.jhydrol.2009.03.031

GUIMARÃES, R. F.; FERNANDES, N. F.; GOMES, R. A. T.; CARVALHO JUNIOR, O. A. Fundamentação teórica do modelo matemático para previsão de escorregamentos rasos Shallow Stability. Revista Espaço \& Geografia, v. 06, n. 2, p. 133 - 150, 2003.

GUIMARÃES, R. F.; MACHADO, W. P.; CARVALHO JÚNIOR, O. A.; MONTGOMERY, D. R.; GOMES, R. A. T.; GREENBERG, H. M.; CATALDI, M.; MENDONÇA, P. C. Determination of Areas Susceptible to Landsliding Using Spatial Patterns of Rainfall from Tropical Rainfall Measuring Mission Data, Rio de Janeiro, Brazil. ISPRS International Journal of Geo-Information, v. 6, n. 10, p. 289, 2017. https://doi.org/10.3390/ijgi6100289

HENGL, T. Finding the right pixel size. Computer \& Geoscience, n. 32, p. 1283 - 1298, 2006. https://doi.org/10.1016/j.cageo.2005.11.008

HODGSON, M. E.; JENSEN, J. R.; SCHMIDT, L.; SCHILL, S.; DAVIS, B. An evaluation of LIDAR- and IFSAR-derived digital elevation models in leaf-on conditions with USGS Level 1 and Level 2 DEMs.

Remote Sensing of Environment, v. 84, n. 2, p. 295 - 308, 2003.

https://doi.org/10.1016/S0034-4257(02)00114-1

HODGSON, M. E.; JENSEN, J. R.; RABER, G.; TULLIS, J.; DAVIS, B. A.; THOMPSON, G.; SCHUCKMAN, K. An Evaluation of Lidar-derived Elevation and Terrain Slope in Leaf-off Conditions. Photogrammetric Engineering \& Remote Sensing, v. 71, n. 7, p. 817 - 823, 2005. https://doi.org/10.14358/PERS.71.7.817

HUTCHINSON, M. F. A locally adaptive approach to the interpolation of digital elevation models. In: INTERNATIONAL CONFERENCE, 3, Workshop on Integrating GIS and Environmental Modeling. Proceedings... Santa Fe, NM: 1996.

HUTSON, S. R. Adapting LiDAR data for regional variation in the tropics: A case study from the Northern Maya Lowlands. Journal of Archaeological Science: Reports, v. 4, p. 252 - 263, 2015. https://doi.org/10.1016/j.jasrep.2015.09.012

IBGE - Instituto Brasileiro de Geografia e Estatística. Censo Demográfico 2010. Rio de Janeiro, 2010. Disponível em < https://censo2010.ibge.gov.br/>. Acesso em: 10 jul. 2020.

JENSEN, J. R. Sensoriamento remoto do ambiente: uma perspectiva em recursos terrestres. São Jose dos Campos, SP: Parênteses, 2011.

KIENZLE, S. The Effect of DEM Raster Resolution on First Order, Second Order and Compound Terrain Derivatives. Transactions in GIS, v. 8, n. 1, p. 83 - 111, 2004. https://doi.org/10.1111/j.1467-9671.2004.00169.x

LEA, N. L. An aspect driven kinematic routing algorithm. In: ANDERSON, A. J.; ABRAHAMS, A. D. Overland Flow: Hydraulics and Erosion Mechanics, Nova lorque: Chapman \& Hall, 1992.

LINDSAY, J. B. Whitebox GAT: A case study in geomorphometric analysis. Computers \& Geosciences, v. 95, p. 75 - 84, 2016. https://doi.org/10.1016/i.cageo.2016.07.003

LIOYD, C. D.; ATKINSON, P. M. Deriving DSMs from LIDAR data with kriging. International Journal of Remote Sensing, v. 12, n. 23, p. 2519 - 2524, 2002. https://doi.org/10.1080/01431160110097998 LOTTE, R. G.; ALMEIDA, C. M.; VALERIANO, M. M. Aquisição do Índice de Saturação do Solo (TWI) para a avaliação de suscetibilidade a movimentos de massa na região de São Sebastião-SP. In: Simpósio Brasileiro de Sensoriamento Remoto, 17, 2015. Anais... João Pessoa: INPE, 2015. Disponível em: <http://www.dsr.inpe.br/sbsr2015/files/p1570.pdf>. Acesso em: 13 jul. 2020. MCGLONE, J. C. Manual of Photogrammetry. Bethesda: ASP\&RS, 2004.

$\begin{array}{llllll}\text { Caminhos de Geografia } & \text { Uberlândia - MG } & \text { v. 22, n. } 84 & \text { dez/2021 } & \text { p. 301-322 } & \text { Página } 320\end{array}$


Potencialidades e limitações do uso de informações altimétricas provenientes de perfilamento à laser em ambiente urbano
Felipe Lima Ramos Barbosa Renato Fontes Guimarães Osmar A. de Carvalho Júnior Roberto A. Trancoso Gomes Erondina Azevedo de Lima

ONU - Organização das Nações Unidas. Departamento de Assuntos Econômicos e Sociais World Urbanization Prospects - The 2018 Revision. Nova lorque, 2019. Disponível em: < https://population.un.org/wup/Publications/Files/WUP2018-Report.pdf> Acesso em: 11 jul. 2020.

PFEIFER, N.; GORTE, B.; ELBERINK, S. O. Influences of vegetation on laser altimetry - analysis and correction approaches. In: THIES, M.; KOCH, B.; SPIECKER, H.; WEINACKER, (Eds.), Proceedings of Nascan, Laser-Scanners for Forest and Landscape Assessment - Instruments. Processing Methods and Applications. International Archives of Photogrammetry and Remote Sensing, v. 36, p. 283 - 287, 2004. Disponível em: <https://www.isprs.org/proceedings/XXXVl/8W2/PFEIFER(2).pdf>. Acesso em: 13 jul. 2020.

POLAT, N.; UYSAL, M.; TOPRAK, A. S. An investigation of DEM generation process based on LIDAR data filtering, decimation, and interpolation methods for an urban area. Measurement, v. 75, p. 50 56, 2015. https://doi.org/10.1016/j.measurement.2015.08.008

QIU, Z.; KENNEN, J. G.; GIRI, S.; WALTER, T.; KANG, Y.; ZHANG, Z. Reassessing the relationship between landscape alteration and aquatic ecosystem degradation from a hydrologically sensitive area perspective. Science of the Total Environment, v. 650, p. 2850 - 2862, 2019.

https://doi.org/10.1016/i.scitotenv.2018.10.036

QUINN, P.; BEVEN, K.; CHEVALLIER, P.; PLANCHON, O. The prediction of hillslope flow paths for distributed hydrological modeling using digital terrain models. Hydrological processes, v. 5, p. 59 79, 1991. https://doi.org/10.1002/hyp.3360050106

SHAN, J; TOTH, C. K. Topographic Laser Ranging and Scanning: Principles and Processing. Nova lorque: CRC Press, $2^{\circ}$ ed, 2018.

SORENSEN, R.; SEIBERT, J. Effects of DEM resolution on the calculation of topographical indices: TWI and its components. Journal of Hydrology, v. 347, n. 1-2, p. 79 - 89, 2007. https://doi.org/10.1016/i.jhydrol.2007.09.001

TARBOTON, D. G. A new method for the determination of flow directions and upslope areas in the grid digital elevation models. Water Resources Research, v. 33, n. 2, p. $309-319,1997$. https://doi.org/10.1029/96WR03137

TARBOTON, D. G. Taudem 5.3 - Terrain Analysis Using Digital Elevation Models. [S.I.]: Utah University, 2015. Disponível em_<https://hydrology.usu.edu/taudem/taudem5/> [programa de computador]. Acesso em: 15 jul. 2020.

TERRACAP - Agência de Desenvolvimento do Distrito Federal. Mapeamento Aerofotogramétrico das áreas urbanas do Distrito Federal - Relatório Técnico do produto 2. Brasília, 2016.

THOMAS, I. A.; JORDAN, P.; MELLANDER, P. E.; FENTON, O.; SHINE, O.; HUALLACHAIN, D. O.; CREAMER, R.; MCDONALD, N. T.; DUNLOP, P.; MURPHY, P. N. C. Improving the identification of hydrologically sensitive areas using LIDAR DEMs for the delineation and mitigation of critical source areas of diffuse pollution. Science of the Total Environment, v. 556, p. $276-290,2016$.

https://doi.org/10.1016/i.scitotenv.2016.02.183

THOMAS, I. A.; JORDAN, P.; SHINE, O.; FENTON, O.; MELLANDER, P. E.; DUNLOP, P.; MURPHY, P. N. C. Defining optimal DEM resolutions and point densities for modelling hydrologically sensitive areas in agricultural catchments dominated by microtopography. International Journal of Applied Earth Observation and Geoinformation, v. 54, p. 38 - 52, 2017. https://doi.org/10.1016/.j.jag.2016.08.012

VAZE, J.; TENG, J.; SPENCER, G. Impact of DEM accuracy and resolution on topographic indices. Environmental Modelling \& Software, v. 25, n. 10, p. 1086 - 1098, 2010. https://doi.org/10.1016/j.envsoft.2010.03.014

WALLIS, C.; WATSON, D.; TARBOTON, D.; WALLACE, R. Parallel Flow-Direction and Contributing Area Calculation for Hydrology Analysis in Digital Elevation Models. In: PDPTA'09 - The 2009 International Conference on Parallel and Distributed Processing Techniques and Applications, Las Vegas, Nevada, USA, 2009.Disponível em:

<https://www.researchgate.net/profile/Robert Wallace9/publication/221133105 Parallel FlowDirection and Contributing Area Calculation for Hydrology Analysis in Digital Elevation Models/li nks/557ed13208aeea18b77952cc/Parallel-Flow-Direction-and-Contributin>. Acesso em: 15 jun. 2020.

$\begin{array}{llllll}\text { Caminhos de Geografia } & \text { Uberlândia - MG } & \text { v. 22, n. } 84 & \text { dez/2021 } & \text { p. 301-322 } & \text { Página } 321\end{array}$


WALTER, M. T.; WALTER, M. F.; BROOKS, E. S.; STEENHUIS, T. S.; BOLL, J.; WEILER, K. Hydrologically sensitive areas: variable source area hydrology implications for water quality risk assessment. J. Soil Water Conserv. v. 55, p. 277 - 284, 2000. Disponível em:

<https://www.jswconline.org/content/55/3/277.short>. Acesso em: 14 jun. 2020.

WU, Y.; GIRI, S.; QIU, Z. Understanding the spatial distribution of hydrologic sensitive areas in the landscape using soil topographic index approach. International Soil and Water Conservation Research, v. 4, p. 278 - 283, 2016. https://doi.org/10.1016/j.iswcr.2016.10.002

YANALAK, M. Effect of gridding method on digital terrain model profile data based on scattered data. Journal of Computing in Civil Engineering, v. 17, n. 1, p. 58-67, 2003.

https://doi.org/10.1061/(ASCE)0887-3801(2003)17:1(58)

Recebido em: 11/09/2020

Aceito para publicação em: 09/03/2021 